\title{
Add-on therapy options in asthma not adequately controlled by inhaled corticosteroids: a comprehensive review Hannu Kankaanranta*1,2, Aarne Lahdensuo ${ }^{2}$, Eeva Moilanen ${ }^{1,3}$ and Peter J Barnes ${ }^{4}$
}

Address: ${ }^{1}$ The Immunopharmacological Research Group, Medical School, University of Tampere, Tampere, Finland, ${ }^{2}$ Department of Pulmonary Diseases, Tampere University Hospital, Tampere, Finland, ${ }^{3}$ Department of Clinical Chemistry, Tampere University Hospital, Tampere, Finland and ${ }^{4}$ Department of Thoracic Medicine, National Heart and Lung Institute, Imperial College, London, UK

Email: Hannu Kankaanranta* - blhaka@uta.fi; Aarne Lahdensuo - aarne.lahdensuo@wlanmail.com; Eeva Moilanen - eeva.moilanen@uta.fi; Peter J Barnes - p.j.barnes@imperial.ac.uk

* Corresponding author

Published: 27 October 2004

Respiratory Research 2004, 5:17 doi:10.1186/1465-9921-5-17
Received: 02 June 2004

Accepted: 27 October 2004

This article is available from: http://respiratory-research.com/content/5/I/I7

(C) 2004 Kankaanranta et al; licensee BioMed Central Ltd.

This is an open-access article distributed under the terms of the Creative Commons Attribution License (http://creativecommons.org/licenses/by/2.0), which permits unrestricted use, distribution, and reproduction in any medium, provided the original work is properly cited.

\begin{abstract}
Many patients with persistent asthma can be controlled with inhaled corticosteroids (ICS). However, a considerable proportion of patients remain symptomatic, despite the use of ICS. We present systematically evidence that supports the different treatment options. A literature search was made of Medline/PubMed to identify randomised and blinded trials. To demonstrate the benefit that can be obtained by increasing the dose of ICS, dose-response studies with at least three different ICS doses were identified. To demonstrate whether more benefit can be obtained by adding long-acting $\beta_{2}$-agonist (LABA), leukotriene antagonist (LTRA) or theophylline than by increasing the dose of ICS, studies comparing these options were identified. Thirdly, studies comparing the different "add-on" options were identified. The addition of a LABA is more effective than increasing the dose of ICS in improving asthma control. By increasing the dose of ICS, clinical improvement is likely to be of small magnitude. Addition of a LTRA or theophylline to the treatment regimen appears to be equivalent to doubling the dose of ICS. Addition of a LABA seems to be superior to an LTRA in improving lung function. However, addition of LABA and LTRA may be equal with respect to asthma exacerbations. However, more and longer studies are needed to better clarify the role of LTRAs and theophylline as add-on therapies.
\end{abstract}

\section{Introduction}

Inhaled corticosteroids (ICS) are the mainstay of current asthma management and should be used in all patients with persistent asthma. Many patients with persistent asthma can be controlled with regular ICS. However, a considerable proportion of patients treated with ICS remain symptomatic, despite the use of low to moderate doses (doses defined according to the ATS classification for adults [1,2]: beclomethasone dipropionate (BDP) 200 - $1000 \mu \mathrm{g} / \mathrm{d}$, budesonide $200-800 \mu \mathrm{g} / \mathrm{d}$ or fluticasone propionate (FP) $100-500 \mu \mathrm{g} / \mathrm{d}$ ) of ICS. Based on the differences in potency and pharmacokinetics the doses could also be defined differently $[3,4]$. Recent treatment guidelines $[1,2,5,6]$ classify these patients as having moderate 
to severe persistent asthma (steps 3 and 4). According to the recent guideline [2] the typical clinical features of step 3 asthma include symptoms daily, nocturnal symptoms at least once a week, exacerbations that may affect activity or sleep, forced expiratory volume in one second $\left(\mathrm{FEV}_{1}\right) 60$ $-80 \%$ of predicted or peak expiratory flow (PEF) between 60 and $80 \%$ of the personal best reading. Daily rescue therapy is usually needed. Typical findings include low values of $\mathrm{PEF}$ or $\mathrm{FEV}_{1}$, a marked variation in daily $\mathrm{PEF}$ recordings and/or a significant response to bronchodilators. Thus, asthma is not adequately controlled, and the treatment needs to be optimized.

According to current guidelines the therapeutic options in the treatment of asthma not adequately controlled by low to moderate doses of ICS are as follows: 1 . Increase in the dose of the ICS, 2. Addition of long-acting $\beta_{2}$-agonist (LABA; formoterol or salmeterol), 3. Addition of a leukotriene receptor antagonist (LTRA; montelukast, pranlukast or zafirlukast) and 4. Addition of theophylline. Currently, the National Heart, Lung and Blood Institute guideline [2] recommends addition of LABA as the first choice and gives the other choices as secondary options, but leave the clinician alone to make the decision without offering comprehensive data to support the different options. Recently, this "step-3" dilemma on the different treatment options has gained attention [7,8]. Several of these options have been separately assessed in several reviews, systematic reviews and metaanalyses [7,9-16]. However, no comprehensive reviews exist on the subject. The aim of our article is to review the evidence that supports the increase in the dose of ICS and use of the different "addon" options. Firstly to demonstrate the benefit that can be obtained by increasing the dose of ICS, dose-response studies with at least three different ICS doses were identified. Secondly, to demonstrate whether more benefit can be obtained by adding LABA, LTRA or theophylline to the treatment than by increasing the dose of ICS, we aimed to identify studies where the addition of a LABA, LTRA or theophylline to the treatment regimen was compared with the addition of a corresponding plabeco to an increased dose (usually doubled dose) of ICS. Thirdly, we aimed to identify studies comparing the different "addon" options. In this review, we hope to help the clinician facing the "step-3 dilemma" by presenting in a systematic way the evidence obtained from randomised clinical trials that supports the use of these different treatment options.

\section{Methods}

The paper reviews studies where participants were adults or adolescents ( $\geq 12$ years) with clinical evidence of asthma not adequately controlled with ICS. The general inclusion criteria in this review were: randomized, blinded and controlled trials with either parallel group or cross-over design published as a full-length paper. Ster- oid-tapering studies were not included as they are difficult to interpret. Studies published in abstract form only were not included. Similarly, studies lasting less than 4 weeks, containing less than 10 patients per group or studies containing a significant proportion $(>10 \%)$ of patients using systemic steroids were excluded. Similarly "add-on" studies where a significant proportion (>10\%) of patients were not using inhaled steroids were excluded.

We made a search of Medline from January 11966 to October 2001. All searches were limited to studies published in the English language. To identify the latest studies published, another search was made by using the drug names (budesonide, beclomethasone, fluticasone, flunisolide, mometasone, triamcinolone, formoterol, salmeterol, montelukast, pranlukast, zafirlukast, theophylline) from Medline on October 2003. The searches were manually (HK) evaluated to identify studies fulfilling the inclusion criteria and full papers were retrieved. In the case of uncertainty based on the abstract full papers were retrieved. All studies fulfilling the inclusion criteria for the ICS dose-response studies or "add-on" studies (see below) were scored for quality using the method described by Jadad et al. [17]. Furthermore, relevant systematic reviews were identified from the Cochrane Library (Issue 2, 2003). In addition, some in vitro results or results from open, non-randomized or uncontrolled trials or meta-analysis of particular relevance to the present topic may be cited.

\section{Inclusion criteria for dose-response studies with ICS}

To find the dose-response studies with ICS the term "antiinflammatory agents, steroidal" was combined with the term: "dose-response relationship, drug" (MeSH), which combination produced 249 papers. To demonstrate the dose-response effect of ICS only controlled studies with at least three different ICS doses and a parallel-group design were included. Studies using consecutive doses of steroids were not included because it makes it impossible to differentiate the dose-response relation from the time course relation of efficacy.

\section{Inclusion criteria for "add-on" studies with long-acting $\beta_{2}$ - agonists, leukotriene antagonists and theophylline}

When the basic search done with the term "anti-inflammatory agents, steroidal" was combined with another made with terms: "salmeterol OR formoterol" it produced 97 papers, when combined with a search made with a term "leukotriene antagonists" (MeSH), it produced 26 papers and when combined with a search with a term "theophylline" (MeSH) it produced 342 papers. Only studies where the addition of LABA, LTRA or theophylline to the treatment with inhaled steroid was compared with the addition of a corresponding placebo to an increased dose (usually double-dose) of inhaled steroid were 
included. In addition, studies comparing the different "add-on" options were identified.

\section{Increasing the dose of inhaled corticosteroid On the design of dose-response studies with ICS}

We identified 14 studies [18-31] assessing the doseresponse relationship of ICS in the treatment of chronic asthma. All included studies were of fair to excellent quality (Jadad score 3-5). The main characteristics of these studies are presented in Table 1 (see Additional file 1). The inclusion criteria in most of these studies were moderate to severe chronic asthma but previous use of small to moderate doses of ICS was not required in all studies. The studies included patients with a relatively wide range of $\mathrm{FEV}_{1} \%$ predicted and based on that these patients belong to steps 2-4 according to the recent guideline [2]. In all except three studies a $\geq 12 \%$ reversibility in $\mathrm{FEV}_{1}$ or PEF in response to a bronchodilator was required. There was 1 study that assessed the dose-response of budesonide, 7 of $\mathrm{FP}, 1$ of BDP, 3 of mometasone furoate, and 2 of triamcinolone acetonide. The studies utilized two main approaches to identify a dose-response relationship. Some studies considered dose-response relationship to be present if the results obtained with the lowest and highest dose of ICS were significantly different, whereas in others the presence or absence of dose-response relationship was characterized with more advanced statistical analysis (e.g. analysis for linear trend or Jonckheere's nonparametric trend test). In this review, both ways of analysis are accepted as evidence for the presence of dose-response. In the following discussion the important difference between the formal dose-response studies presented in this review and the results reported in some meta-analysis is that the data of the meta-analyses may result from studies assessing one or more doses of ICS and comparing their effects with placebo or baseline. Thus, the data derived from some the published meta-analyses $[9,11,14,32]$, although showing a dose-response effect, is obtained by combining different doses from several studies, and is not resulting from a strict dose-response relationship study. In addition, the data obtained using metaanalysis may be derived only from one or two studies.

\section{Overview on lung function and symptoms in the 14 included studies}

Studies with ICS show a statistically significant doseresponse effect for morning $\mathrm{PEF}$ and $\mathrm{FEV}_{1}$ in the treatment of chronic asthma in $9(69 \%)$ and $5(31 \%)$ studies of the 14 studies included, respectively (Table $2 a$, see Additional file 1). However, statistical analysis of dose-dependency fails to show any significant dose-related effect for FVC in $5(71 \%)$ studies of 7 where it was analysed. Similarly, no statistical dose-dependency was found for evening PEF in $6(50 \%)$ studies out of 12 where it was analysed (Table $\mathbf{2 a}$, see Additional file 1 ). The total or daytime symptom scores show a statistically significant dose-response effect in $5(38 \%)$ out of 13 studies, whereas nighttime symptom score showed a dose-dependency in only three (25\%) studies out of 13 where it was analysed. A dose-response for the rescue $\beta_{2}$-agonist use was found in 4 (33\%) out of 12 studies where it was analyzed (Table $2 \mathbf{b}$, see Additional file 1). The difference between the highest and the lowest dose of ICS was most often statistically significant for morning PEF (7/12 studies; $58 \%$ ) and to a lesser extent for evening PEF (3/10 studies; $30 \%), \mathrm{FEV}_{1}$ and total or daytime symptom scores (both 2/12 studies; 16.7\%), night-time symptom score and rescue $\beta_{2}$-agonist use (both $1 / 11$ studies; $9 \%)$ and FVC (0/6 studies; $0 \%)$. Similarly, the difference between the two consecutive doses of ICS was very seldom statistically significant (Table $2 \mathrm{ab}$, see Additional file 1). Thus, taken together, the results suggest that morning and evening PEF and $\mathrm{FEV}_{1}$ are more sensitive to show a statistically significant dose-response effect for ICS, whereas symptom scores and rescue $\beta_{2}$-agonist use are in general less sensitive to the increase in steroid dose. However, this conclusion may also be influenced by the duration of treatment. Inclusion of relatively short studies in this review, may either under- or over-estimate the dose-response differences depending on the outcome measure being used.

\section{Beclomethasone dipropionate - studies included in this systematic review}

The dose-response relationship of the effects of BDP (100 $-800 \mu \mathrm{g} / \mathrm{d}$ in two different formulations) was evaluated in asthmatic subjects who had deterioration in asthma control after discontinuation of ICS [18]. There was a statistically dose-dependent effect on morning PEF, $\mathrm{FEV}_{1}$, FVC, days free from wheeze or chest tightness and $\beta_{2}$-agonist use, but not on evening PEF or nights free from asthma related sleep disturbance (Table $2 \mathbf{a b}$, see Additional file 1). The dose-response effects detected in this study may reflect the fact that the patient population was carefully identified to show a well-defined responsiveness to ICS. Thereafter ICS were withdrawn to induce a clinically meaningful deterioration of asthma control. Thus, the design may not directly reflect clinical practice, where a patient is symptomatic, despite the use of low to moderate doses of ICS.

\section{Beclomethasone dipropionate - other literature}

A recent meta-analysis [10] analysed the dose-response effect of BDP in the treatment of chronic asthma. Eleven studies with variable methodological quality involved 1614 subjects were included in the analysis. Most of the endpoints were based on only 1-2 studies. In asthmatic patients not treated with oral steroids a small advantage of BDP $800 \mu \mathrm{g} / \mathrm{d}$ over $400 \mu \mathrm{g} / \mathrm{d}$ was apparent for improvement in $\mathrm{FEV}_{1}$ and morning PEF and reduction in nighttime symptom score compared to baseline. Studies that 
assessed BDP $1000 \mathrm{v} 500 \mu \mathrm{g} / \mathrm{d}$ and BDP $1600 \mathrm{v} 400 \mu \mathrm{g} / \mathrm{d}$ demonstrated a significant advantage of the higher dose compared to the lower dose for percentage improvement in airway responsiveness to histamine and $\mathrm{FEV}_{1}$ compared to baseline. No differences between higher and lower daily doses of BDP were apparent for daytime symptoms, withdrawals due to asthma exacerbations or oropharyngeal side effects.

\section{Budesonide - studies included in this systematic review}

A 6 weeks dose-response study in Japanese asthmatics previously not on ICS showed that increasing the dose of budesonide (200-800 $\mu \mathrm{g} / \mathrm{d})$ [19] results in a dose-related improvement in morning and evening PEF and daytime and nighttime symptom scores, but not for $\mathrm{FEV}_{1}$. In this study, there was no statistically significant difference between the doubling doses of budesonide (Table 2ab, see Additional file 1). Instead, even the lowest dose of budesonide $(200 \mu \mathrm{g} / \mathrm{d})$ was superior to placebo in the case of morning and evening PEF and daytime and nighttime symptom scores, but not for $\mathrm{FEV}_{1}$.

\section{Budesonide - other literature}

In a randomised, double-blind, placebo-controlled study of parallel-group design lasting 12 weeks four different doses of budesonide (200, 400, 800 and $1600 \mu \mathrm{g} / \mathrm{d}$ were compared in patients suffering from moderate to severe asthma. This study was not included in the systematic analysis due to a high proportion of patients on oral glucocorticoids $(15.6 \%)$. Increasing the dose of budesonide [33] results in a dose-related improvement in morning PEF and $\mathrm{FEV}_{1}$, but not in evening PEF, FVC, symptom scores or rescue $\beta_{2}$-agonist use. Instead, even the lowest dose of budesonide $(200 \mu \mathrm{g} / \mathrm{d})$ was superior to placebo for all parameters studied. The improvement induced by these low doses is much greater than the difference between the lowest and highest doses of budesonide studied, despite the 8-fold difference in the dose (Figure 1) [33]. There was a statistically significant difference only between the lowest $(200 \mu \mathrm{g} / \mathrm{d})$ and the highest $(1600 \mu \mathrm{g} /$ d) doses of budesonide when morning PEF or FEV 1 were analysed. Instead, the lowest $(200 \mu \mathrm{g} / \mathrm{d})$ or the highest dose $(1600 \mu \mathrm{g} / \mathrm{d})$ did not differ from the two medium doses $(400-800 \mu \mathrm{g} / \mathrm{d})$. When evening PEF, FVC, daytime or nighttime asthma symptom scores or the use of rescue medication were analysed, there was no significant differences between any of the studied budesonide doses [33].

The dose-relationship of budesonide in the treatment of chronic asthma is a subject of a recent Cochrane review [12]. In this meta-analysis including both children and adults $(n=3907)$ in non-oral steroid-treated mild to moderately severe asthmatics no clinically worthwhile differences in $\mathrm{FEV}_{1}$, morning PEF, symptom scores or rescue $\beta_{2}$-agonist use were apparent across a dose range of
200-1600 $\mu \mathrm{g} / \mathrm{d}$. However, in moderate to severe asthma there was a significant reduction in the likelihood of trial withdrawal due to asthma exacerbation with budesonide $800 \mu \mathrm{g} / \mathrm{d}$ compared with budesonide $200 \mu \mathrm{g} / \mathrm{d}$. The reviewers also conclude that budesonide exhibits a significant improvements favouring high dose $(1600 \mu \mathrm{g} / \mathrm{d})$ over low dose $(200 \mu \mathrm{g} / \mathrm{d})$ for improvement in $\mathrm{FEV}_{1}$ in severe asthma [12]. Another recent meta-analysis combining 3 placebo-controlled studies with at least two different budesonide doses demonstrated a statistically significant dose-response for morning PEF and $\mathrm{FEV}_{1}$ but not for evening PEF [14].

Fluticasone propionate - studies included in this systematic review The dose-dependency of FP has been studied in seven studies in patients with mild to moderate asthma. In two of the studies, patients were previously not on ICS (Table 1 , see Additional file 1 ). The difference between the highest and lowest dose was 4 - to 20-fold. In all studies almost all parameters improved significantly better with all doses of FP as compared with placebo. Only three studies $[20,21,26]$ show a dose-response effect on morning PEF, only two studies $[20,26]$ show a dose-response relationship for evening PEF and rescue medication use and only one study [20] shows a dose-response relationship for $\mathrm{FEV}_{1}$, FVC and daytime symptom score (Table 2ab, see Additional file 1). When different doses of FP (50-200$1000 \mu \mathrm{g} / \mathrm{d}$ ) were studied in a randomized, double-blind dose-response setting, there was no difference in $\mathrm{FEV}_{1}$, FVC, evening PEF, symptom scores, use of rescue medication or the number of night awakenings between the lowest and highest FP dose, despite a 20-fold difference in the dose [21]. Only for morning PEF was the high $(1000 \mu \mathrm{g} /$ d) dose of FP better than the two lower doses, whereas even the lowest dose of FP $(50 \mu \mathrm{g} / \mathrm{d})$ was significantly better than placebo in improving all these parameters.

In a dose-response study [20] with patients with symptomatic chronic asthma $(n=672)$ patients were randomized to four different doses of FP $(100,200,400,800 \mu \mathrm{g} / \mathrm{d})$. FP improved lung function and symptoms in a dose-related manner. The linear trend for doubling the dose of FP was calculated to be as follows: morning PEF increased $4.3 \mathrm{~L} /$ min (95\% CI 1.8-6.8) and $\mathrm{FEV}_{1}$ increased $0.03 \mathrm{~L} \mathrm{(95 \%} \mathrm{CI}$ 0-0.05 in two weeks). How does this translate into clinical practice? When assessing a response to a bronchodilator or when assessing a response to inhaled or oral steroid an improvement of $10-20 \%$ above the previous values is often considered significant. Thus, in the above study, this would mean $>36 \mathrm{~L} / \mathrm{min}$ increase in morning PEF values. Recently, the average minimal patient perceivable improvements have been estimated as $18.8 \mathrm{~L} / \mathrm{min}$ for PEF and $0.23 \mathrm{~L}_{\text {for }} \mathrm{FEV}_{1}$ [34]. Based on that the increase in lung function obtained by doubling the dose of 


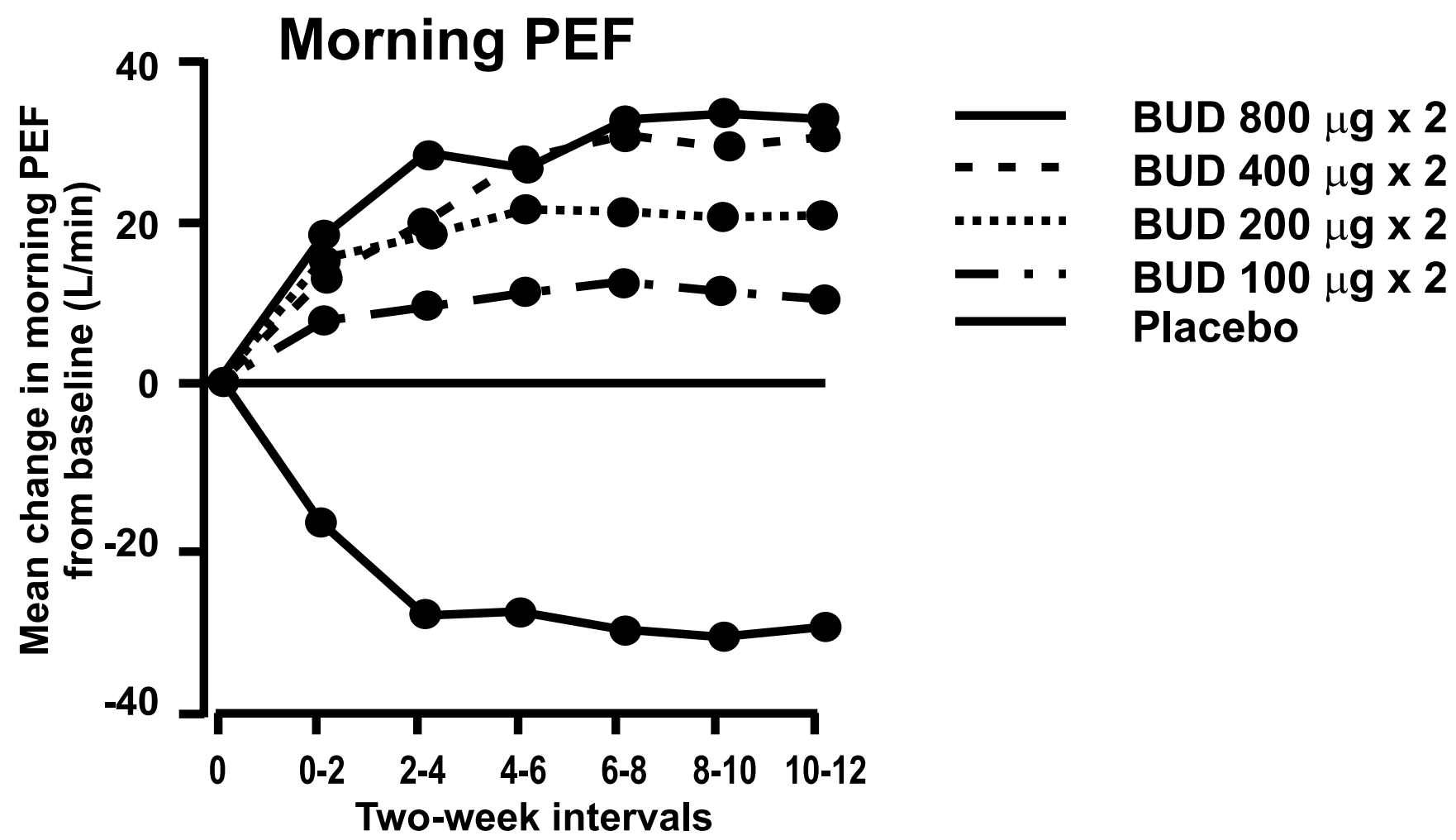

Figure I

Mean change from baseline in morning peak expiratory flow (PEF) in patients treated with placebo or various doses of budesonide. A significant dose-response effect is seen. However, it should be noted that the difference between placebo and low-dose budesonide is greater than the difference between low-dose budesonide and high-dose budesonide and that there is no statistically significant difference between the various doses of budesonide. Reproduced from reference 33 with permission.

fluticasone in the above study seems to be only of very limited clinical benefit.

\section{Fluticasone propionate - other literature}

In a recent meta-analysis [9] the dose-response relation of inhaled FP in adolescents or adults with asthma in eight studies [ $n=2324]$ employing 2-3 different doses of inhaled FP were analysed. The dose-response curve for the raw data began to reach a plateau at around 100-200 $\mu \mathrm{g} /$ $\mathrm{d}$ and peaked by $500 \mu \mathrm{g} / \mathrm{d}$. A negative exponential model for the data indicated that $80 \%$ of the benefit at $1000 \mu \mathrm{g} /$ $\mathrm{d}$ was achieved at doses of $70-170 \mu \mathrm{g} / \mathrm{d}$ and $90 \%$ by $100-$ $250 \mu \mathrm{g} / \mathrm{d}$. A quadratic meta-regression showed that the maximum achievable efficacy was obtained by doses of around $500 \mu \mathrm{g} / \mathrm{d}$. Another recent meta-analysis [11] of 28 studies with 5788 patients (children and adults) with chronic asthma evaluated the dose-response effect of FP, compared to placebo. Evidence for a dose-response effect was apparent for likelihood of trial withdrawal due to lack of efficacy, change in $\mathrm{FEV}_{1}$, morning PEF, evening PEF, nighttime awakening score and physician-rated efficacy. It is important to appreciate that this was only evident when improvements over placebo were compared for the highest dose of FP $(1000 \mu \mathrm{g} / \mathrm{d})$ and lowest dose of FP $(100 \mu \mathrm{g} /$ d). There were no significant differences when any other doses were compared (e.g. FP $200 \mathrm{v} 100 \mu \mathrm{g} / \mathrm{d}$, FP $500 \mathrm{v}$ $200 \mu \mathrm{g} / \mathrm{d}$, FP $1000 \mathrm{v} 500 \mu \mathrm{g} / \mathrm{d})$. Sixty percent (0.31 L; 95\% CI $0.27-0.36 \mathrm{~L}$ ) of the effect on $\mathrm{FEV}_{1}$ with FP $1000 \mu \mathrm{g} / \mathrm{d}$ (0.53 L; 95\% CI 0.43-0.63 L) was achieved with tenth of the dose. No dose-response effect was apparent for change in symptom score or for rescue $\beta_{2}$-agonist use [11]. Another recent meta-analysis from the same authors [32] found a statistically significant advantage of FP $200 \mu \mathrm{g} / \mathrm{d}$ over $100 \mu \mathrm{g} / \mathrm{d}$ for morning PEF (6 L/min; 95\% CI 1-10 L/ min), evening PEF ( $6 \mathrm{~L} / \mathrm{min}, 95 \% \mathrm{CI} \mathrm{2-11} \mathrm{L/min})$ and night-time awakening score $(0.17,95 \%$ CI $0.04-0.30)$, but not for $\mathrm{FEV}_{1}$, daily symptom score, night-time awakenings and daily use of rescue $\beta_{2}$-agonist use. No significant advantage was obtained with the use of FP at doses of 400-500 $\mu \mathrm{g} / \mathrm{d}$ over $200 \mu \mathrm{g} / \mathrm{d}$ for morning or evening PEF, $\mathrm{FEV}_{1}$, daily symptom score or rescue $\beta_{2}$-agonist use. Patients treated with higher dose $(800-1000 \mu \mathrm{g} / \mathrm{d})$ of FP 
achieved significantly greater improvements in morning PEF (22 L/min, 95\% CI 15-29 L/min) and evening PEF (13 L/min, 95\% CI 6-19 L/min) compared to the lower dose $(50-100 \mu \mathrm{g} / \mathrm{d})$. Another recent meta-analysis [14] including eight trials with at least 2 different doses of FP demonstrated a statistically significant dose-response in morning PEF, evening PEF and asthma symptom score but not in $\mathrm{FEV}_{1}$ or $\beta_{2}$-agonist use.

Mometasone furoate and triamcinolone acetonide - studies included in this systematic review

Mometasone furoate is a corticosteroid closely related to FP and is being investigated in a dry powder inhalation formulation for the treatment of asthma [35]. Studies with mometasone furoate [27-29] show a dose-related efficacy in the treatment of mild to moderate asthma when morning PEF is analysed (Table 2a, see Additional file 1). Interestingly, even doubling doses of mometasone furoate produced statistically significant improvements in morning and evening PEF (Table 2a, see Additional file 1) [27-29]. Occasionally, a statistically significant dosedependency or difference between the highest and lowest dose was found for evening PEF, $\mathrm{FEV}_{1}$ or daytime or total symptom score. In contrast, no significant dose-dependency was found for FVC, nighttime symptom score or rescue $\beta_{2}$-agonist use (Table 2ab, see Additional file 1).

Linear trend analyses showed a dose-response for triamcinolone acetonide (TAA) in the treatment of moderate to severe asthma across the dose-range of 150 to $600 \mu \mathrm{g} / \mathrm{d}$ or 200 to $1600 \mu \mathrm{g} / \mathrm{d}$ for most variables in the two studies included in this review (Table 2ab, see Additional file 1) $[30,31]$. Occasionally, a statistically significant difference was reported even between two consecutive doses of TAA. As compared with placebo, therapeutic activity was generally evident at doses of 150-200 $\mu \mathrm{g}$ daily for all variables with significant clinical efficacy demonstrated for all doses.

Mometasone furoate and triamcinolone acetonide - other literature A four-week randomised, double-blind, double-dummy and parallel group study [36] comparing the efficacy and safety of mometasone furoate administered by metered dose inhaler $(112,400$ and $1000 \mu \mathrm{g} / \mathrm{d})$ with BDP $(336 \mu \mathrm{g} /$ d) and placebo recruited adult patients with moderate asthma $(\mathrm{n}=395)$. The patients were required to have a stable ICS dose, $\mathrm{FEV}_{1}$ or $50-90 \%$ and a bronchodilator response of $\geq 15 \%$ in absolute $\mathrm{FEV}_{1}$ at baseline. This study reported significantly better improvement in $\mathrm{FEV}_{1}$, FVC and morning PEF with doses of 400 and $1000 \mu \mathrm{g} / \mathrm{d}$ than with $112 \mu \mathrm{g} / \mathrm{d}$. Also, physician's evaluation of asthma symptoms, but not salbutamol use was significantly better with dose $1000 \mu \mathrm{g} / \mathrm{d}$ than with $112 \mu \mathrm{g} / \mathrm{d}$. This study, although fulfilling the criteria for dose-response study as defined in materials and methods, was excluded from the systematic evaluation, as the published statistical analysis did not include any formal dose-response analysis, and the reported difference between different mometasone doses always required a statistically significant difference to the active comparator BDP.

In contrast to the results presented in this review (Table 2ab, see Additional file 1), a meta-analysis [14] including 2 studies with mometasone furoate $(200 \mu \mathrm{g} / \mathrm{d}$ versus 400 $\mu \mathrm{g} / \mathrm{d}$ ) failed to show any significant dose-response in $\mathrm{FEV}_{1}$. In the meta-analysis, there was not enough data to analyse other parameters than $\mathrm{FEV}_{1}$. The 3 studies [27-29] included in this review were not included in the metaanalysis [14]. The data suggests that $200 \mu \mathrm{g} / \mathrm{d}$ of mometasone furoate may be a relatively small dose. As both the inhaler device and mometasone have not been available for the treatment of asthma, it is difficult to define their exact position in the treatment of asthma, although there are data to suggest that a total daily dose of $400 \mu \mathrm{g}$ of mometasone furoate administered with dry powder inhaler may be equal to total daily dose of $500 \mu \mathrm{g}$ of FP via a Diskhaler or a daily dose of $800 \mu \mathrm{g}$ budesonide via a Turbuhaler $[28,29]$.

A placebo-controlled, double-blind parallel-group study assessed the effects of three different doses of TAA (450, 900 and $1800 \mu \mathrm{g} / \mathrm{d}$ for 12 weeks; delivered using a nonchlorofluorocarbon propellant) in patients with chronic symptomatic asthma and using ICS [37]. The data for all variables $\left(\mathrm{FEV}_{1}, \mathrm{FEF}_{25-75}\right.$, morning and evening $\mathrm{PEF}$, symptom scores and rescue salbutamol use) shows that even the lowest dose significantly differs from placebo, and there appears to be no clear dose-response. However, no formal statistical analysis was reported for the presence of a dose-response and thus this study is not included in Tables 1-2. A recent meta-analysis [14] including 3 studies with TAA, demonstrated a statistically significant doseresponse in morning PEF, evening PEF and asthma symptom score, but not in $\mathrm{FEV}_{1}$.

\section{Conclusions on the effects of ICS on lung function and asthma symptoms}

Taken together these results indicate that the change in the ICS dose from low dose to moderate dose is at the flat part of the ICS dose-response curve for most lung function and symptom parameters studied (Figure 2). Furthermore, it appears that the low and moderate doses of currently used ICS are in the flat part of the steroid dose-response curve. Thus, it is predicted that doubling the dose of ICS is not sufficient to significantly improve lung function or reduce symptoms. Rather, the data suggest that the increase in the dose of ICS should be at least 4-fold to produce a clinically significant improvement in variables such as symptoms, use of rescue $\beta_{2}$-agonists, PEF or lung function. However, the steepness of the dose-response curve for different 


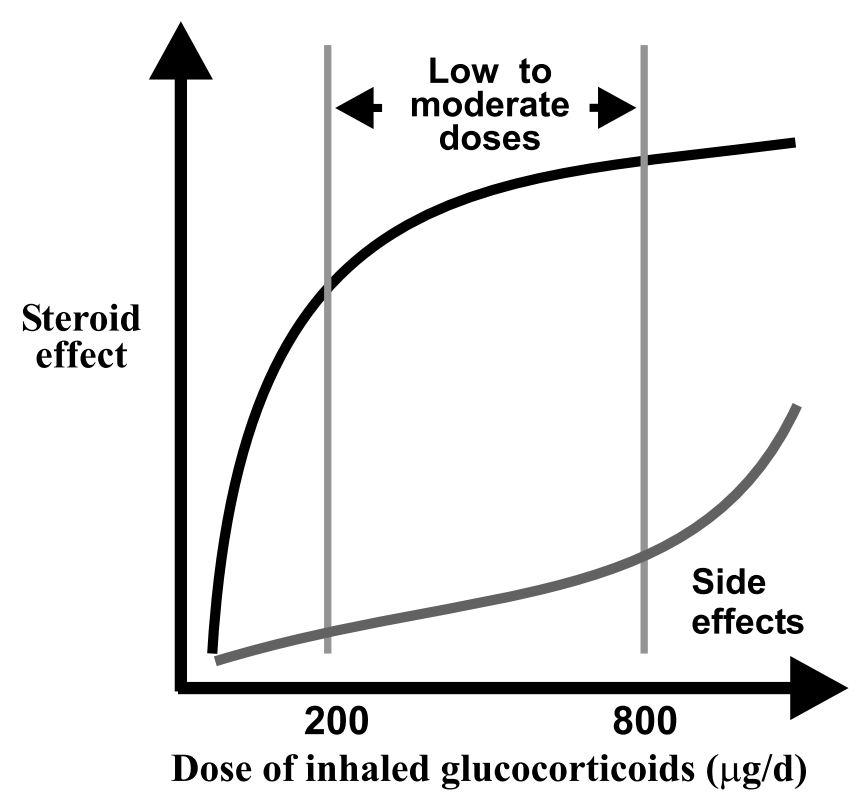

Figure 2

The dose-response curve of inhaled glucocorticoids.

outcomes may vary. For example, an open dose-response evaluation of different sequential doses of budesonide in patients with mild-to-moderate asthma (38) shows that the dose-response curves for $\mathrm{FEV}_{1} / \mathrm{PEF}$ and $\mathrm{FEF}_{25-75}$ are not identical. Similarly, the dose-response curves of budesonide on adenosine monophosphate (AMP) and methacholine bronchial challenges were significantly different [38]. It should also be noted that patients often receive higher doses of ICS in their daily routine treatment than required [3].

The studies discussed above present mean data for groups of patients, but do not address the issue of differences in responsiveness to the anti-inflammatory effects of corticosteroids between individual patients. It may be possible that increasing the dose of ICS may be beneficial for some patients.

\section{Is there a dose-response in the anti-inflammatory effects of ICS?}

Studies included in this systematic review

We were not able to identify any studies that would have studied the dose-dependency of the anti-inflammatory effects of ICS in asthma and would have satisfied the inclusion criteria for the present review.

\section{Other literature}

In a study [39] with patients with chronic asthma $(n=66)$ treated with moderate doses of ICS the dose-dependency of consecutive doses of budesonide $(800,1600$ and 3200 $\mu \mathrm{g} / \mathrm{d}$ ) and FP (500, 1000 and $2000 \mu \mathrm{g} / \mathrm{d}$ ) were studied. Budesonide increased methacholine $\mathrm{PD}_{20}$ from 259 to $467 \mu \mathrm{g}$ and FP from 271 to $645 \mu \mathrm{g}$, both showing a dosedependency. However, no statistical comparison was made between individual doses. The $\mathrm{PD}_{20}$ was increased 1.67-fold and 1.96-fold when the patients were switched from the lowest dose to the highest dose of budesonide and FP, respectively. An apparently dose-dependent decrease in the blood eosinophil count was obtained with budesonide but not with FP treatment [39]. In contrast, no significant differences were observed for either treatment, when morning or evening PEF, symptom scores, and consumption of $\beta_{2}$-agonist were analysed. Allergen $\mathrm{PC}_{15}$ and methacholine $\mathrm{PC}_{20}$ values were determined before and after treatment with budesonide at 200, 400 and $800 \mu \mathrm{g} / \mathrm{d}$ for 7 days in a double-blind, randomized and cross-over study ( 6 day washout period) in eleven atopic subjects with inhalation allergy [40]. The allergen $\mathrm{PC}_{15}$ and methacholine $\mathrm{PC}_{20}$ were significantly larger for all doses of budesonide as compared with placebo, but there was no significant difference between the 3 doses of budesonide. In an open trial with patients with moderate to severe asthma the effects of progressively increasing doses of budesonide $(400,800,1600$ and $2400 \mu \mathrm{g} / \mathrm{d}$ ) were studied [41]. Budesonide decreased the blood eosinophil count in a dose-dependent manner. In a doubleblind, randomized placebo-controlled study combining two separate studies, the dose-dependency of the antiinflammatory effects of budesonide (100, 400 and 1600 $\mu \mathrm{g} / \mathrm{d})$ was assessed in patients with mild asthma $(\mathrm{n}=31)$. Based on trend analysis, there were dose-dependent changes in exhaled $\mathrm{NO}$, sputum eosinophils and $\mathrm{PC}_{20}$ to inhaled budesonide but a plateau response of exhaled $\mathrm{NO}$ was found at a dose of $400 \mu \mathrm{g} / \mathrm{d}$ [42]. In a study with a novel ICS ciclesonide, its effects were studied in a parallelgroup, double-blind, placebo-controlled, randomized cross-over study (washout period 3-8 weeks) in patients ( $n=29)$ with mild to moderate asthma [43]. Compared with placebo, ciclesonide for 14 days $(100,400$ and 1600 $\mu \mathrm{g} / \mathrm{d}$ ) reduced airway responsiveness to AMP by 1.6, 2.0 and 3.4 doubling doses, respectively, and this effect was dose-dependent. A significant reduction in the percentage of eosinophils in induced sputum was observed after 400 and $1600 \mu \mathrm{g}$ daily ciclesonide, but this was not dosedependent. Sputum eosinophil cationic protein (ECP) was significantly reduced after $400 \mu \mathrm{g}$ daily ciclesonide only, and no dose-dependent effect was seen. In a recent single-cohort, prospective placebo-controlled study with four 1 week periods with nonsteroid-treated asthmatic patients $(n=15)$ the effects of different doses of BDP $(100,400$ and $800 \mu \mathrm{g} / \mathrm{d})$ were measured on $\mathrm{FEV}_{1}$, exhaled nitric oxide (FENO) and methacholine $\mathrm{PC}_{20}$ [44]. All doses of BDP resulted in a significant change in $\mathrm{FEV}_{1}$ and methacholine $\mathrm{PC}_{20}$ from baseline or placebo treatment, 
but with no significant separation of active BDP doses. All doses of BDP resulted in a significant change in FENO from placebo treatment, but with significant separation of only the $100 \mu \mathrm{g}$ and $800 \mu \mathrm{g}$ doses by FENO. Another study assessed the dose-response relationship of the antiinflammatory effects of BDP $(50,100,200$ and $500 \mu \mathrm{g} / \mathrm{d})$ in the treatment of mild to moderate asthma for 8 weeks in a randomised, placebo-controlled, double-blind trial of parallel-group design [45]. Maintenance ICS therapy was discontinued and patients were randomised to different treatment groups and inflammatory markers such as exhaled NO, sputum eosinophil counts and $\mathrm{PD}_{15}$ to saline were followed. There was a significant linear relationship between BDP dose and exhaled NO concentration, FEV $_{1}$ and changes in sputum eosinophils at the end of treatment. In contrast no relationship was found between BDP dose and $\mathrm{PD}_{15}$ to saline. However, the results of this study may be confounded because the patients were treated with oral prednisolone for two days in the beginning of the study.

In a recent randomized and double-blinded study, 12 atopic mild stable asthmatic subjects were treated with placebo or mometasone furoate $(100,200$ and $800 \mu \mathrm{g} / \mathrm{d})$ for six days [46] in a cross-over fashion. All three doses of MF demonstrated similar attenuation of early responses and allergen-induced airway hyperresponsiveness relative to placebo with no dose-response relationship. In contrast, the late maximal \% fall in $\mathrm{FEV}_{1}$ after placebo treatment was $24 \%$ and was significantly reduced in a dosedependent manner to $12 \%, 11 \%$ and $6 \%$ for the 100,200 and $800 \mu \mathrm{g}$ daily treatments. The allergen-induced sputum eosinophilia $\left(\times 10^{4}\right.$ cells $\left./ \mathrm{ml}\right) 24 \mathrm{~h}$ after challenge during placebo treatment was 60.2 and was significantly reduced to 24.0, 15.3 and 6.2 for the 100, 200 and $800 \mu \mathrm{g}$ daily treatments, respectively. Although a statistically significant dose-response relationship was present, the difference between the lowest and highest dose (8-fold difference) for late maximal fall in $\mathrm{FEV}_{1}$ or allergeninduced sputum eosinophilia was less than the difference between placebo and the lowest dose of MF.

Taken together, the results suggest that there is tendency towards slightly higher anti-inflammatory efficacy with higher doses of ICS. At the moment there are only a few studies that assess the dose-dependency of the antiinflammatory effects of ICS. Most of these studies included only small numbers of patients. However, despite the 4-8-16-fold differences in the doses of ICS studied, it has not been easy to demonstrate the dosedependency of the anti-inflammatory effects of inhaled glucocorticoids. Thus, based on the scarce published evidence we would predict that doubling of the commonly used low to moderate doses of ICS is likely to produce only a small increase in the anti-inflammatory effect, sug- gesting that inflammation may be suppressed in most patients by relatively low doses of ICS.

\section{Is there a dose-response with the adverse effects of ICS?}

Glucocorticoids suppress corticotrophin levels, which may eventually lead to atrophy of the adrenal cortex and diminished levels of endogenous cortisol. The diminished levels of endogenous cortisol or reduced cortisol excretion have been used as markers of systemic activity of ICS. These systemic effects may include osteoporosis, behavioural effects, growth suppression, posterior subcapsular cataracts, risk for ocular hypertension and glaucoma as well as skin thinning and bruising [47]. In the following sections the literature on the dose-related effects of different steroids on HPA axis as well as on local adverse effects is discussed.

\section{Studies included in the systematic review}

Of the 14 studies included in this review, in 8 the effects on HPA-axis suppression were analysed. No data on the effects of BDP, budesonide or TAA on HPA-axis were reported. Six of the 7 randomised, double-blind doseresponse studies with FP also analysed its effect on HPA axis, measuring either basal morning cortisol levels, postcosyntropin stimulation test levels or urinary excretion of cortisol metabolites (Table 2b, see Additional file 1). Only one study reported a statistically significant doseresponse effect ( $3 \%$ decrease per doubling dose of FP) in morning plasma cortisol levels [20] and one study [21] reported slight transient reductions in urinary free cortisol and urinary 17-hydroxy steroids in the group receiving the highest dose of FP $(1000 \mu \mathrm{g} / \mathrm{d})$. However, in 5 studies made with FP, no dose-related effects on HPA-axis suppression were described (Table $\mathbf{2} \mathbf{b}$, see Additional file 1 ). There was no indication for the dose-dependent HPA-axis suppression in 2 studies with mometasone furoate. One needs to note that these studies were not planned and powered to detect differences in systemic or adverse effects.

\section{Beclomethasone dipropionate - other literature}

The dose-related effects of HFA-BDP (200-800 $\mu \mathrm{g} / \mathrm{d})$ were studied in 43 steroid-naïve asthmatic patients in a randomized double-blind fashion for 14 days [48]. When the HFA-BDP dose increased a greater decrease in the percent change from baseline in steady state $24 \mathrm{~h}$ urinary free cortisol was found suggesting a dose-response. Despite the observed statistically significant differences between placebo and the two highest dose-groups in mean percent change in $24 \mathrm{~h}$ urinary free cortisol, only one patient among all the treatment groups fell below the reference range for this parameter. In another small, randomized study 26 steroid-naïve asthmatic patients were treated with increasing doses of BDP $(400-1600 \mu \mathrm{g} / \mathrm{d})$ [49]. Only the highest dose of BDP produced a significant 
suppression of $24 \mathrm{~h}$ urinary free cortisol. In a recent Cochrane review [10], the dose-response relationship of BDP on HPA axis function was analysed. Only two small studies with adult patients not treated with oral steroids were identified, and showed no effect on morning plasma cortisol by two to five-fold increase in the BDP dose.

\section{Budesonide - other studies}

A randomized double-blind study with consecutive dose design [39] comparing FP (500-2000 $\mu \mathrm{g} / \mathrm{d})$ and budesonide $(800-3200 \mu \mathrm{g} / \mathrm{d})$ reported that budesonide, but not FP (or at least to a lesser extent) reduced $24 \mathrm{~h}$ urine cortisol excretion, plasma-cortisol and serum osteocalcin in a dose-related manner. Similar results have been reported from an open, randomized, parallel group trial with budesonide at doses of 400, 800, 1600 and $2400 \mu \mathrm{g} / \mathrm{d}$ for 2 weeks at each dose level, in adult patients with moderate to severe asthma [41]. Budesonide decreased the $24 \mathrm{~h}$ urinary cortisol excretion, serum cortisol and osteocalcin in a dose-dependent manner. In a randomized, doubleblind parallel-group study [33], budesonide $(1600 \mu \mathrm{g} / \mathrm{d}$ for 12 weeks) induced a mean change from baseline in synthetic corticotrophin (cosyntrophin)-stimulated plasma cortisol levels that was significantly different from placebo and the lowest dose of budesonide. However, the difference from placebo was only $10 \%$, and all other doses of budesonide were not statistically different from placebo. In contrast, the mean basal morning plasma cortisol levels among different budesonide treatment groups and placebo did not differ. In a randomized cross-over study [50], budesonide $(1600 \mu \mathrm{g} / \mathrm{d})$ reduced serum osteocalcin and blood eosinophil count as compared with placebo, but these effects were not dose-dependent. In contrast, budesonide (400-1600 $\mu \mathrm{g} / \mathrm{d}$ ) had no significant effects on adrenal function as assessed by 8 am serum cortisol or overnight urinary cortisol excretion. In a recent open study, budesonide (400-1600 $\mu \mathrm{g} / \mathrm{d}$ ) was given to patients with mild to moderate asthma $(n=26)$ sequentially for 3 weeks each dose, a total of 9 weeks [38]. There was a significant dose-related suppression of morning cortisol levels and overnight urinary cortisol values, but not of serum osteocalcin. For example, the percentages of patients with a stimulated plasma cortisol response less than $500 \mathrm{nM}$ were $7 \%$ at baseline, $13 \%$ at $400 \mu \mathrm{g} / \mathrm{d}, 40 \%$ at $800 \mu \mathrm{g} / \mathrm{d}$ and $66 \%$ at $1600 \mu \mathrm{g} / \mathrm{d}$. The authors reported that the proportions of patients with a beneficial airway response together with a minimal systemic response - that is, an optimal therapeutic index - were approximately 50\% at all three doses of budesonide. However, the proportion of patients with a good airway response together with a marked systemic response - that is, a suboptimal therapeutic index - increased from $4 \%$ at low dose to $38 \%$ at high dose [38]. In a recent Cochrane meta-analysis, statistically significant, dose-dependent suppression by budesonide of 24 hour urinary free cortisol excretion and serum cortisol post synthetic ACTH infusion over the dose range $800-3200 \mu \mathrm{g} / \mathrm{d}$ were apparent, but the authors concluded that the clinical significance of these findings is unclear [12].

\section{Fluticasone propionate - other literature}

FP has also been shown to suppress 8 am serum cortisol and urinary cortisol/creatinine ratio in a dose-dependent manner in a single-blind placebo-controlled cross-over study for 9 days in patients $(n=12)$ with mild to moderate asthma [51]. Similar dose-dependent suppression of adrenocortical activity was reported in four other studies with patients with mild to moderate asthma from the same research group [52-55]. Interestingly, the suppressive effects of FP on adrenocortical activity were greater than those observed on osteocalcin or eosinophils.

A Cochrane review [11] collected data on the effects of FP on HPA-axis function. Significant differences were not apparent between any daily dose of FP in the range of $100-1000 \mu \mathrm{g} / \mathrm{d}$ and placebo on basal plasma cortisol values or urinary cortisol excretion. However, the authors were not able to make a meta-analysis of the cortisol values. In another Cochrane review [32] the same authors found no evidence for dose-dependent suppression of HPA function. However, no decent meta-analysis could be made due to limited availability of data. In contrast to these findings another meta-analysis [47] found that FP exhibits a significantly steeper dose-related systemic bioavailability than BDP, budesonide, or triamcinolone when 21 studies of urinary cortisol levels and 13 studies of suppression of 8 am plasma cortisol levels were analysed. Thus, there clearly exists a discrepancy in the published literature concerning the systemic effects of FP.

Based on the recent Cochrane review and meta-analysis [32] it seems obvious that there is a dose-response relationship in the appearance of local side-effect hoarseness and/or dysphonia so that FP at doses of $400-500 \mu \mathrm{g} / \mathrm{d}$ and $800-1000 \mu \mathrm{g} / \mathrm{d}$ has a significantly higher risk than at lower doses (50-100 $\mu \mathrm{g} / \mathrm{d})$. Similarly FP at doses of 50$100 \mu \mathrm{g} / \mathrm{d}$ induces significantly less oral candidiasis than at doses of $800-1000 \mu \mathrm{g} / \mathrm{d}$. However, there seemed to be no significant difference in the incidence of sore throat/pharyngitis between any of the FP doses. Another systematic review [16] collected data from fluticasone studies and calculated NNT (number needed to treat) to prevent worsening of asthma and NNH (number needed to harm) to induce oral candidiasis. Three patients needed to be treated with fluticasone $100 \mu \mathrm{g} / \mathrm{d}$ to prevent worsening of asthma (NNT 3), and for fluticasone $1000 \mu \mathrm{g} / \mathrm{d}$ the NNT was 2.1 patients. In contrast, the dose-response curve for side effects was steep. For a dose of fluticasone $100 \mu \mathrm{g} / \mathrm{d}$, oral candidiasis developed in one of every 90 subjects 
treated (NNH 90), whereas the NNH for fluticasone 1000 $\mu \mathrm{g}$ and $2000 \mu \mathrm{g}$ daily were 23 and 6 , respectively.

\section{Triamcinolone acetonide - other literature}

In two randomized studies, TAA in the dose range of 400$1600 \mu \mathrm{g} / \mathrm{d}[50,51]$ did not significantly affect 8 am serum cortisol or the $24 \mathrm{~h}$ or overnight urinary excretion of corticosteroid metabolites. In an open non-controlled 6 months study with $400-800-1600 \mu \mathrm{g} / \mathrm{d}$ TAA the plasma cortisol levels before and after cosyntrophin injection were analysed in patients with asthma [56]. Although all treatment regimens caused some reduction in the $24 \mathrm{~h}$ excretion of corticosteroid products, none of the mean values was below the normal ranges and no significant suppression in the cosyntrophin test was seen. The mean data indicated that TAA had overall no significant effect on adrenal function at any dose or at any time. However, three patients exhibited some reduction in adrenal function. In another small, randomized study 26 steroid-naïve asthmatic patients were treated with increasing doses of TAA $(800-3200 \mu \mathrm{g} / \mathrm{d})$ [49]. Only the highest dose of TAA produced a significant suppression of $24 \mathrm{~h}$ urinary free cortisol.

\section{Conclusions on the effects of ICS on HPA axis and local side effects}

Taken together, the data on the systemic adverse effects of ICS is conflicting and seems also to reflect the study design. Several studies have measured only the basal morning cortisol levels or levels after stimulation with high cosyntrophin doses. However, these may be insensitive markers for HPA-axis suppression [47]. Different, a possibly more sensitive endpoint could be plasma cortisol profile during 20-24 h period, which has been shown to be affected by a short course of fluticasone and/or budesonide or even after single inhaled doses [57-59]. There is disagreement between the relative potency of budesonide and FP on HPA-axis function. In addition to the different ways to measure HPA-axis function, this may be due to the use of different inhalers, duration of the treatment period, the selection of the patient group or different design and sponsoring of the studies by pharmaceutical companies. In addition there are differences in the delivery of ICS between normal subjects and patients with asthma and in patients with severe versus mild asthma [60-62]. Although generally safe, it appears that there is at least some degree of dose-dependency in the HPA-axis effects of inhaled steroids. Some smaller studies $[39,41,54]$ suggest that there is a significant decrease in the therapeutic index with higher doses of ICS. Recently, a statistical meta-analysis using regression was performed for parameters of adrenal suppression in 27 studies [47]. Marked adrenal suppression, and thus a marked risk for systemic adverse effects, occurs at doses of ICS above 1500 $\mu \mathrm{g} / \mathrm{d}$ (budesonide and BDP) or $750 \mu \mathrm{g} / \mathrm{d}$ (FP), although there is a considerable degree of inter-individual susceptibility. Meta-analysis showed significantly greater potency for dose-related adrenal suppression with FP compared with BDP, budesonide, or TAA. The author concludes that ICS in doses above $1500 \mu \mathrm{g} / \mathrm{d}(750 \mu \mathrm{g} / \mathrm{d}$ for FP) may be associated with a significant reduction in bone density [47]. Long-term, high-dose ICS exposure increases the risk for posterior subcapsular cataracts, and to a much lesser degree, the risk for ocular hypertension and glaucoma. Skin bruising, which correlates with the degree of adrenal suppression, is most likely to occur with high-dose exposure [47].

\section{Adding a long acting- $\beta_{2}$-agonist (LABA) The rationale}

LABA provide long-lasting relaxation of airway smooth muscle, while the ICS provide potent topical anti-inflammatory action. In addition to these complementary actions, $\beta_{2}$-agonists may have several other actions that may contribute to their efficacy in relieving asthma symptoms. $\beta_{2}$-Agonists inhibit plasma exudation in the airways by acting on $\beta_{2}$-receptors on postcapillary venule cells. They inhibit the secretion of bronchoconstrictor mediators from airway mast cells and may inhibit release of mediators from eosinophils, macrophages, T-lymphocytes and neutrophils. In addition, $\beta_{2}$-agonists may have an inhibitory effect on the release of neuropeptides from sensory nerves [63]. Corticosteroids may also increase the expression of $\beta_{2}$-receptors in inflammatory cells to overcome the desensitisation in response to chronic $\beta_{2}$-agonist exposure [64]. In addition, LABA may prime the glucocorticoid receptor facilitating activation by corticosteroids $[65,66]$.

\section{Design of 12 LABA add-on studies included in the review}

The literature search identified 3 studies with formoterol [67-69] and 9 studies with salmeterol [70-78]. All these studies included adult or adolescent patients with symptomatic asthma. Generally, patients used low to moderate doses of inhaled glucocorticoids. In two studies $[68,73]$ previous use of ICS was not required. In all studies PEF or $\mathrm{FEV}_{1}$ reversibility of at least $10-15 \%$ was required (Table 3 , see Additional file 1). Diurnal or period PEF variation $>15 \%$ was required in four studies. $\mathrm{FEV}_{1}$ of $>(40)-50 \%$ of predicted and a clearly positive symptom score was required in most studies (Table 3, see Additional file 1). In general, the mean $\mathrm{FEV}_{1}$ ( $\%$ predicted) varied between 61 and $87 \%$ in different studies, being $61-70 \%$ in 4 studies, $70-80 \%$ in 3 studies, $81-87 \%$ in two studies and was not reported in three studies. The mean absolute PEF values varied from 299 to $404 \mathrm{~L} / \mathrm{min}$ and $\mathrm{FEV}_{1}$ from 2.12 to $2.54 \mathrm{~L}$ (Table 5, see Additional file 1). Thus, the patient population in these studies represents mainly those with moderate to severe persistent asthma. This as well as the fact that patients with recent exacerbations are excluded 
may produce a selection bias, compared with the real life. In one study [78] patients were required to have at least two exacerbations during the previous year to be eligible for the inclusion in the study. One study [68] was performed in patients mainly affected with mild persistent asthma. In salmeterol and formoterol studies, the comparison dose of ICS was increased 2-2.5 (-4)-fold, whereas in the formoterol study [67] the comparison dose of budesonide was 4-fold higher (Table 4, see Additional file 1). Another significant difference between formoterol and salmeterol studies is that in the formoterol [67] study the main outcome parameter was the incidence of exacerbations whereas the salmeterol studies mainly focused on lung function and asthma symptoms. Most studies allowed a constant dose of theophylline but not oral steroid use (Table 3, see Additional file 1). Six out of the 12 studies excluded patients having previous exacerbations (generally during previous month). Only 2 studies lasted one year $[67,68]$, whereas most studies lasted at least 24 weeks. Most reports did not identify whether the study were performed by respiratory specialists or general practitioners. All studies were financially supported by pharmaceutical companies.

\section{Lung function and asthma symptoms}

Formoterol - studies included in this systematic review

The addition of formoterol was compared with the increase (4-fold) in the dose of inhaled budesonide (from $200 \mu \mathrm{g} / \mathrm{d}$ to $800 \mu \mathrm{g} / \mathrm{d}$ ) in patients with moderate to severe symptomatic chronic asthma [67]. The patients $(\mathrm{n}=852)$ in this study had a $\mathrm{FEV}_{1}$ of at least $50 \%$ of predicted (mean $75-76 \%$ ) with an increase in $\mathrm{FEV}_{1} \geq 15 \%$ after inhalation of terbutaline. Addition of formoterol was superior to the increase in steroid dose in increasing $\mathrm{FEV}_{1}$ and morning PEF (Figure 3A; Table 5, see Additional file 1). Similarly, addition of formoterol was equal or superior to the 4-fold increase in ICS dose in reducing day- or night-time symptom scores or rescue medication use (Table 6, see Additional file 1). Most importantly, the effect of formoterol was sustained over the one-year treatment period. In this study, no statistical comparison was made between the low-dose budesonide + formoterol and high dose budesonide groups.

Another study [69] compared the addition of formoterol ( $4.5 \mu \mathrm{g}$ bid) to a small dose of budesonide $(160 \mu \mathrm{g} / \mathrm{d})$ in single inhaler $\left(\right.$ Symbicort $\left.{ }^{\circledR}\right)$ with an increased dose of budesonide $(400 \mu \mathrm{g} / \mathrm{d})$ in adults with mild to moderate asthma (mean $\mathrm{FEV}_{1}$ 81-82\%) not fully controlled on low doses of ICS alone. The increase in mean morning and evening PEF was significantly higher for budesonide/formoterol compared with budesonide alone. In addition, the percentage of symptom-free days and asthma control days were significantly improved in the budesonide/formoterol group. Budesonide and formoterol decreased the relative risk of an asthma exacerbation by $26 \%$ as compared with higher dose budesonide alone.
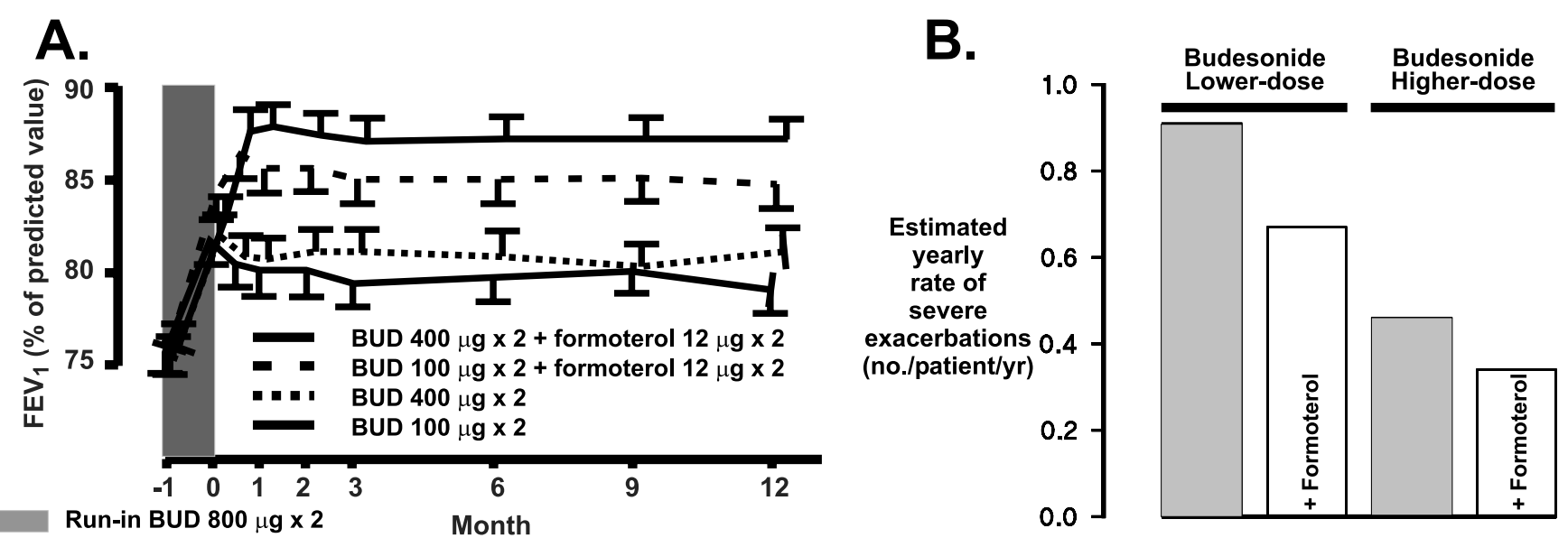

\section{Figure 3}

Formoterol add-on study showing forced expiratory volume in one second $\left(F E V_{1}\right)$ (panel $A$, from ref 64 with permission) and the estimated yearly rates (no. patients/year) of severe asthma exacerbations in the different treatment groups of the study (panel B). For estimated yearly rate of exacerbations, the $\mathrm{P}$-values given were formoterol vs placebo $\mathrm{P}=0.0 \mathrm{I}$ and lower vs higher dose of budesonide $\mathrm{P}<0.00 \mathrm{I}$. 
The results of the formoterol study [67] on the benefits of addition of formoterol were confirmed in patients with mild asthma (mean $\mathrm{FEV}_{1} 86-87 \%$ of predicted and using approximately 1 rescue inhalation per day) [68]. In this study, the addition of formoterol was superior to doubling the dose of budesonide in increasing $\mathrm{FEV}_{1}$ and morning PEF in the patients already treated with a low dose of ICS, but not in steroid-naïve patients (Table 5), or in reducing the percentage of days with symptoms, number of rescue inhalations or nights with awakenings in the patients with mild persistent asthma already treated with low doses of ICS (Table 6, see Additional file 1).

A subgroup of the patients participating in the formoterol study [67] was analysed for asthma quality of life parameters using the Asthma Quality of Life Questionnaire (AQLQ) [79]. Following randomisation there was a significant increase in the AQLQ score only in the group with higher budesonide + formoterol group. Although the patterns of mean responses for AQLQ scores and for the clinical variables were very similar, correlations between change in AQLQ scores and change in clinical measures over the randomized period were only weak to moderate (maximum $r=0.51$ ). The data confirm that the benefit from the addition of formoterol is sustained. However, instead of improving pulmonary function parameters patients are usually more interested in how their normal everyday life and activities are limited by the disease. The analysis of AQLQ parameters and their comparison with the clinical data in that analysis also suggest that if only pulmonary function parameters are to be analysed, the benefits of addition of LABA to the treatment may be overestimated. Also, it should be noted that no correlation has been found between measures of pulmonary function and daytime asthma symptoms [80].

\section{Formoterol - other literature}

As compared with the abovementioned three studies, similar superiority of addition of formoterol on morning PEF, rescue medication use and asthma symptoms were reported in an open randomised parallel-group study comparing the addition of formoterol to the low-dose BDP with 2-fold higher dose of BDP in patients suffering from symptomatic asthma, despite the use of inhaled BDP [81].

\section{Salmeterol - studies included in this systematic review}

Addition of salmeterol as compared with the increase in the dose of ICS BDP or FP has been studied in 9 randomised parallel group studies with 3651 patients with moderate to severe persistent asthma (Tables 3 and 4, see Additional file 1). Addition of salmeterol improved $\mathrm{FEV}_{1}$ better than increasing the dose of ICS 2-4-fold in 5 studies (analysed in 6 studies) and mean morning PEF in 7 studies (analysed in 9 studies), respectively (Table 5, see Addi- tional file 1). Similarly, addition of salmeterol was significantly better than the increase in the dose of ICS in increasing the number of days or nights without symptoms or without rescue medication or reducing day- or night-time symptom score as well as daytime or nighttime rescue medication use in most studies (Table 6, see Additional file 1). However, although addition of salmeterol seems to be superior to increased dose of ICS, a statistically significant difference was not always reached (Tables 5 and 6, see Additional file 1) in the single studies when $\mathrm{FEV}_{1}$, morning PEF, asthma symptom scores or rescue medication use were analysed. Another feature typical of these studies is that the results favour the addition of salmeterol more at early time points and this difference is reduced as the study proceeds.

\section{Salmeterol - other literature}

Most of the studies mentioned above, (except ref [72]), have recently been analysed in a meta-analysis [13]. In addition, the published meta-analysis included 1 study (n $=488$ ) that remains unpublished at the present. At baseline these patients $(n=3685$, aged $\geq 12)$ used BDP 200 $400-1000 \mu \mathrm{g} / \mathrm{d}$ or FP $200-500 \mu \mathrm{g} / \mathrm{d}$. The addition of salmeterol to those doses was compared with increasing the dose of BDP or FP up to 2-2.5-fold. The mean $\mathrm{FEV}_{1}$ was $<75 \%$ in most studies included in the meta-analysis and a reversibility of $\geq 10-15 \%$ in PEF or FEV $\mathrm{Ffter}_{1}$ inhalation of short-acting bronchodilator was required for inclusion in all but three studies. In patients receiving salmeterol the morning PEF was $22-27 \mathrm{~L} / \mathrm{min}$ greater and $\mathrm{FEV}_{1}$ was $0.10-0.08 \mathrm{~L}$ greater after three to six months of treatment, compared to the response to increased steroids. Similarly, the mean percentage of days and nights without symptoms was increased $12-15 \%$ and 5\%, respectively, as well as the mean percentage of days and nights without need for rescue treatment increased $17-20 \%$ and $8-9 \%$, respectively.

\section{Effect of LABA on asthmatic inflammation}

The results of the above mentioned studies favour the addition of a LABA instead of increasing the dose of ICS in patients not adequately controlled with low to moderate doses of ICS. However, there have been concerns that regular use of inhaled $\beta_{2}$-agonists may mask an increase in the underlying airway inflammation in asthma. Also, some proinflammatory effects have been described for $\beta_{2}$ agonists such as delay of constitutive eosinophil apoptosis [82] or reversal of corticosteroid-induced apoptosis [83]. Furthermore, development of tolerance to their protective effects against various asthma-provoking stimuli has been reported. There is some disagreement whether the addition of formoterol or salmeterol changes the level of pulmonary inflammation in patients already treated with inhaled glucocorticoids or whether they may even mask the inflammation. Three studies [84-86] do not 
indicate any significant increase in the inflammatory indices following addition of formoterol or salmeterol, whereas treatment of asthma with salmeterol with concomitant steroid tapering has been shown to increase the numbers of eosinophils in sputum [87].

\section{Formoterol - studies included in this systematic review}

In a randomised, double-blind and parallel-group study $(n=61)$ with similar inclusion and exclusion criteria than in the formoterol add-on study [67], the effect of adding formoterol $(12 \mu \mathrm{g}$ bid) to a low dose of budesonide (200 $\mu \mathrm{g} / \mathrm{d})$ was compared with a higher dose of budesonide $(800 \mu \mathrm{g} / \mathrm{d})$ for 1 year after a run-in with budesonide $(1600 \mu \mathrm{g} / \mathrm{d})$ for 4 -wk [84]. Budesonide $(1600 \mu \mathrm{g} / \mathrm{d})$ during run-in significantly reduced median sputum eosinophils. No significant changes in the proportion of eosinophils, other inflammatory cells, or ECP levels in sputum were observed over the ensuing one year treatment with formoterol + budesonide $(200 \mu \mathrm{g} / \mathrm{d})$ or higher dose budesonide $(800 \mu \mathrm{g} / \mathrm{d})$. Clinical asthma control was not significantly different between both groups.

\section{Salmeterol - other literature}

In a small study $(\mathrm{n}=9)$ with asthma patients using regular inhaled glucocorticoids and inhaled salbutamol for symptom relief, the addition of salmeterol for 8 weeks was studied in a double-blind crossover placebo-controlled protocol [86]. Bronchoalveolar lavage (BAL) cell profile, albumin and tryptase levels, percentages of $\mathrm{CD}^{+}$and CD8+ lymphocytes and lymphocyte activation as assessed as proportions of lymphocytes expressing HLA-DR were measured in BAL samples before and after treatment. There were no significant changes after salmeterol treatment. In another double-blind, parallel-group, placebocontrolled study [85] the effect of addition of salmeterol (50 $\mu \mathrm{g}$ bd) or fluticasone $(200 \mu \mathrm{g} / \mathrm{d})$ for 12 weeks was studied in 45 symptomatic patients with asthma who were receiving ICS (range 100-500 $\mu \mathrm{g} / \mathrm{d}$ ). Bronchial biopsies and BAL were analysed before and after the treatment. After treatment with salmeterol there was no deterioration of airway inflammation, as assessed by mast cell, lymphocyte, or macrophage numbers in BAL or biopsies, but a significant fall in EG1-positive eosinophils in the lamina propria was found, which was not seen after treatment with FP. The only cellular effect of added FP was a decrease in BAL lymphocyte activation as assessed as proportions of lymphocytes expressing HLA-DR. There was a concurrent improvement in clinical status, more marked with salmeterol than with increased ICS. These two studies thus suggest that adding salmeterol to ICS is not associated with increased airway inflammation. In another study in 13 asthmatic individuals requiring $\geq 1500 \mu \mathrm{g}$ ICS daily, the steroid sparing and "masking" effects of salmeterol versus placebo were studied in a randomised, placebo-controlled, double-blind and crossover trial [87].
Subjects were re-stabilised on their original dose of ICS for $4 \mathrm{wk}$ before crossover to the alternative treatment. Corticosteroid doses were reduced weekly until criteria were met for an exacerbation or the corticosteroid was fully withdrawn. Mean ICS dose was reduced significantly more $(87 \%)$ during salmeterol treatment, than with placebo (69\%). Sputum eosinophils increased before exacerbation, despite stable symptoms, $\mathrm{FEV}_{1}$ and PEF. In the week before clinical exacerbation, sputum eosinophil counts were higher in the salmeterol-treatment arm as compared with placebo, whereas there were no differences in $\mathrm{PC}_{20}$ or serum ECP. Five subjects showed $>10 \%$ sputum eosinophilia before exacerbation during salmeterol treatment, compared to two receiving placebo. This suggests that the use of salmeterol allowed subjects to tolerate a greater degree of inflammation without increased symptoms or reduced lung function. Thus, during progressive reduction of ICS the bronchodilator and symptom-relieving effects of salmeterol may mask increasing inflammation and delay awareness of worsening asthma. These findings strengthen guideline recommendations that LABA should not be described as sole anti-asthma medication and that they should be used as "add-on" therapy rather than for steroid tapering purposes.

The effect of addition of salmeterol ( $50 \mu \mathrm{g}$ bd), FP (200 $\mu \mathrm{g} / \mathrm{d}$ ) or placebo for 3 months on airway wall vascular remodelling has been studied in 45 symptomatic patients with asthma who were receiving treatment with ICS (range 400-1000 $\mu \mathrm{g} / \mathrm{d}$ ) [88]. Bronchial biopsies were analysed before and after treatment. There was a decrease in the density of vessels of lamina propria after treatment only in the salmeterol group compared to baseline. There was no significant change within the FP or placebo groups and no treatment was associated with increased airway wall vascularity.

\section{Asthma exacerbations}

If there were a marked masking of pulmonary inflammation by LABA, one would expect to see an increase in the number and severity of asthma exacerbations during their long-term use. There is some difficulty in comparing the different studies done with formoterol and salmeterol as the definition of exacerbation varies. In formoterol studies $[67,68]$ a severe exacerbation was defined as need for treatment with oral corticosteroids, as judged by the investigator, or hospital admission or emergency treatment for worsening of asthma or a decrease in morning PEF $>25 \%-$ $30 \%$ from baseline on two consecutive days. In contrast, in the salmeterol "add-on" studies the exacerbation was not defined at all or was more loosely defined for example as "a clinical exacerbation", "any worsening of asthma symptoms requiring a change in prescribed therapy, other than increased use of rescue medication" or "any asthma event that required treatment with oral or parenteral steroids". 

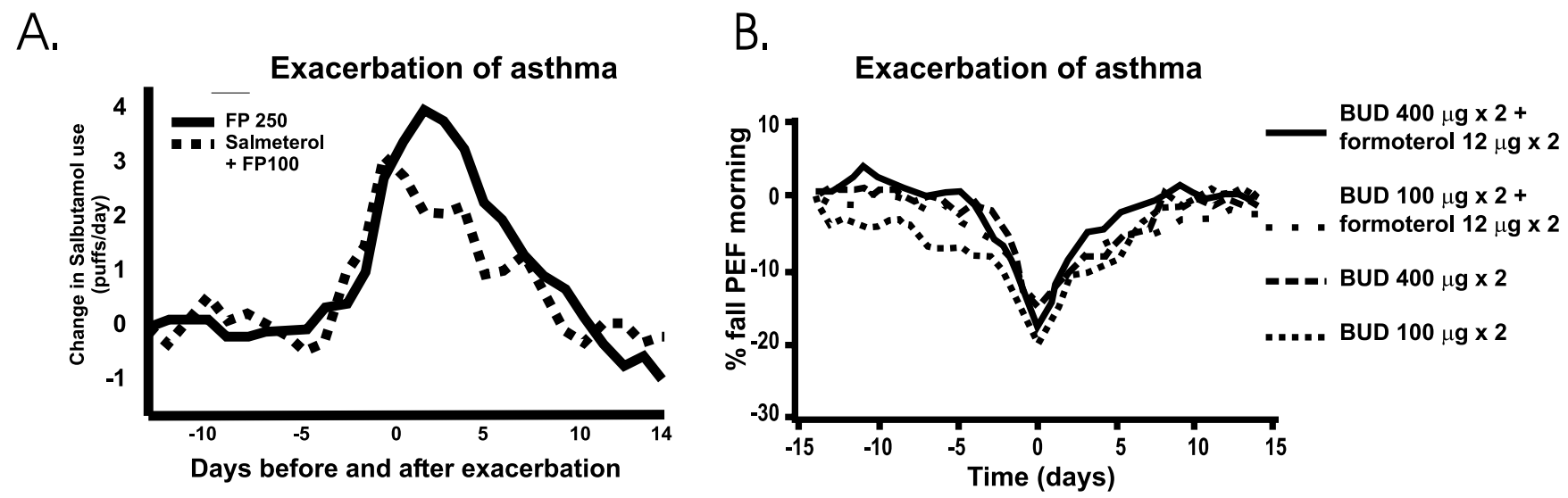

Figure 4

A. Change in supplemental salbutamol use before and after exacerbation in patients treated with fluticasone and salmeterol combination or with high-dose fluticasone (with permission from ref 90), B. Change in morning PEF (percent fall from day - I4) over the $14 \mathrm{~d}$ before and $14 \mathrm{~d}$ after an exacerbation in relation to treatment as analyzed from a subgroup of a FACET study (with permission from ref 89).

Formoterol - studies included in this systematic review

In the formoterol study [67] the main outcome parameter was the rate of exacerbations during combination therapy. The results show that the 4-fold increase in the dose of budesonide reduced the rates of severe and mild exacerbations by $49 \%$ and $37 \%$, respectively, whereas addition of formoterol to the lower dose of budesonide reduced the rates of severe and mild exacerbations by $26 \%$ and $40 \%$, respectively. Patients treated with formoterol and the higher dose of budesonide had the greatest reductions, $63 \%$ and 62\%, respectively (Figure 3B; Table 7, see Additional file 1). This suggests that if frequent asthma exacerbations are a major problem, increasing the dose of ICS may help to reduce the number of exacerbations. The results of the formoterol study [67] as well as the salmeterol meta-analysis [13] suggest that addition of LABA has divergent effects on asthma control: it is superior to the increased steroid dose in improving lung function, but is equal or less efficient in reducing exacerbations (Figure $3 \mathrm{AB})$. The data also suggest that to achieve a better control of asthma exacerbations, the dose of ICS should be increased 4-fold. When 425 exacerbations of the formoterol study [67] were analysed [89], the use of higher dose of ICS or the use of formoterol was shown not to affect the pattern of change in PEF values or in symptoms during asthma exacerbation (Figure 4B).

In contrast to that described in moderate to severe asthma, in the other formoterol study [68] addition of formoterol ( $6 \mu \mathrm{g}$ bid) to either the lower $(200 \mu \mathrm{g} / \mathrm{d})$ or higher $(400$ $\mu \mathrm{g} / \mathrm{d})$ dose of budesonide in patients suffering from mainly mild asthma reduced the risk of the first asthma exacerbation by $43 \%(\mathrm{RR}=0.57,95 \%$ CI $0.46-0.72)$. There was also a significant $52 \%$ reduction in the rate of severe exacerbations $(\mathrm{RR}=0.48 ; 95 \% \mathrm{CI} 0.39-0.59)$. In addition, significant improvement was observed for the rate of severe exacerbations $(\mathrm{RR}=0.58,95 \%$ CI $0.44-$ $0.76)$. Thus, the data suggest that there may be a difference in the effect of ICS and formoterol on the exacerbations between mild and moderate to severe asthma so that in mild asthma addition of LABA may be more efficient in preventing exacerbations, whereas in moderate to severe asthma increasing the dose of ICS may be more efficient (Table 7, see Additional file 1). However, the formoterol studies $[67,68]$ are not fully comparable in that way that in the other study [67] the increase in the dose of budesonide was 4-fold whereas in the other study [68] it was 2fold.

Another study [69] compared the addition of formoterol $(4.5 \mathrm{mg} / \mathrm{d})$ to a small dose of budesonide $(160 \mu \mathrm{g} / \mathrm{d})$ in single inhaler $\left(\right.$ Symbicort $\left.{ }^{\boxplus}\right)$ with an increased dose of budesonide $(400 \mu \mathrm{g} / \mathrm{d})$ in adults with mild to moderate asthma (mean $\mathrm{FEV}_{1}$ 81-82\%) not fully controlled on low doses of ICS alone. Budesonide/formoterol combination significantly decreased the relative risk of an asthma exacerbation by $26 \%$ as compared with higher dose budesonide alone. In contrast, the estimated risk of having a severe exacerbation was $6 \%$ lower in patients treated with budesonide/formoterol compared with those receiving budesonide alone, but this was not statistically significant. 
Salmeterol - studies included in this systematic review

Only two studies $[70,78]$ of those included in this systematic review reported the actual monthly or annual rates for moderate or severe exacerbations. In those studies there were no significant differences in the yearly rate of exacerbations or percentages of patients experiencing at least exacerbation. The other studies generally reported the percentages of patients experiencing at least one exacerbation (Table 7). In salmeterol studies, the data were presented mostly in a form, which did not allow us to calculate the yearly rate of exacerbations.

\section{Salmeterol - other literature}

In the salmeterol studies lasting 3-6 months the numbers of patients with exacerbations were analysed. The metaanalysis [13] revealed that fewer patients experienced any exacerbation with salmeterol (difference 2.7\%), and the proportion of patients with moderate or severe exacerbations was also lower (difference 2.4\%). Thus, to prevent one exacerbation 37-41 patients should be treated with salmeterol instead of increasing the dose of ICS. Rather than indicating salmeterol being superior, the result suggests that there is no increased risk for exacerbations with the use of salmeterol. Unfortunately, in most salmeterol studies the severity and/or yearly incidence of exacerbations was not analysed. As one patient can experience more than one asthma exacerbation during the study, the parameter used in the salmeterol studies (proportion of patients experiencing an exacerbation) may not reflect the actual number of exacerbations. Another factor that may affect our interpretation of the effect of these therapies on asthma exacerbations is that in 6 of the 12 LABA studies, patients could be withdrawn from the study if they experienced $>1-5$ exacerbations (Table 7, see Additional file $1)$. This may underestimate the total incidence of exacerbations, as those patients experiencing several exacerbations were excluded from analysis. However, these are the patients the "add-on" therapies are most frequently prescribed.

Recently, the exacerbation rates and clinical measures of asthma worsening were assessed in an analysis combining results from two double-blind studies $(\mathrm{n}=925)$ comparing addition of salmeterol to low-dose-FP with increasing the dose of FP 2.5-fold [90]. The addition of salmeterol resulted in a significantly lower rate $(0.23$ vs. 0.39 per patient per year) of exacerbations compared with higher dose FP. Salmeterol combined with low-dose FP was significantly more protective than 2.5-fold higher dose of FP in preventing asthma exacerbations, as assessed by the time to first exacerbation. In both groups clinical indicators of worsening of asthma showed parallel changes before asthma exacerbation, and greater improvements in morning PEF, supplemental salbutamol use and asthma symptom score were observed after exacerbation with sal- meterol compared with higher dose FP (Figure 4A). Thus, the ability to detect deteriorating asthma and the severity of exacerbation is not negatively affected by salmeterol.

\section{Adverse effects of LABA}

The addition of LABA to the treatment regimen usually results in a slight increase in those pharmacologically predictable adverse events such as tremor and tachycardia. However, generally these do not lead to the discontinuation of the treatment. In the formoterol studies [67-69], no significant differences were reported on the adverse effects between the groups, but no detailed data was presented. Also, in the salmeterol studies [70-78], the incidence of adverse events was very low and generally was not different between the treatment groups. Although LABA appear to be generally very safe, one should not forget that they are generally not suitable for patients with symptomatic coronary heart disease or hyperthyroidism and may provoke more severe adverse events such as supraventricular tachycardias, atrial fibrillation and extrasystoles. Rarely hypersensitivity reactions and painful muscular cramps may occur. Also one should note that the "add-on" studies included in this review are not originally planned and powered to detect significant differences in the adverse effects.

\section{Adding a leukotriene receptor antagonist (LTRA) Rationale}

Cysteinyl leukotriene receptor-antagonists (LTRA), such as montelukast, pranlukast and zafirlukast, are a new class of asthma medication, whose role in the stepwise management of asthma has not yet been fully established. Leukotriene antagonists blunt the obstructive response and have weak anti-inflammatory activity. In some studies corticosteroids are not very effective inhibitors of cysteinyl leukotriene pathways, at least when assessed by their inability to reduce cysteinyl leukotriene concentrations $[91,92]$ and thus combination of these therapeutic classes may offer some benefit.

Montelukast - studies included in this systematic review

We identified one randomised, double-blind, parallelgroup 16 week study (Jadad score 3 ) comparing the addition of montelukast $(10 \mathrm{mg} / \mathrm{d})$ to budesonide $(800 \mu \mathrm{g} / \mathrm{d})$ with doubling the dose of budesonide $(1600 \mu \mathrm{g} / \mathrm{d})$ in patients inadequately controlled on inhaled budesonide $(800 \mu \mathrm{g} / \mathrm{d}, \mathrm{n}=448)$ [93]. The inclusion criteria were: patients (aged 15-75 years) who were not optimally controlled as judged by the investigators in spite of a regular ICS (600-1200 $\mu \mathrm{g} / \mathrm{d}$ for BDP, budesonide, TAA, flunisolide or $300-800 \mu \mathrm{g} / \mathrm{d}$ for FP). Patients were required to have $\mathrm{FEV}_{1} \geq 50 \%$ predicted at visits 1 and 3 , with a $\geq 12 \%$ bronchodilator response and symptoms requiring $\beta$-agonist treatment of at least 1 puff/day during the last 2 


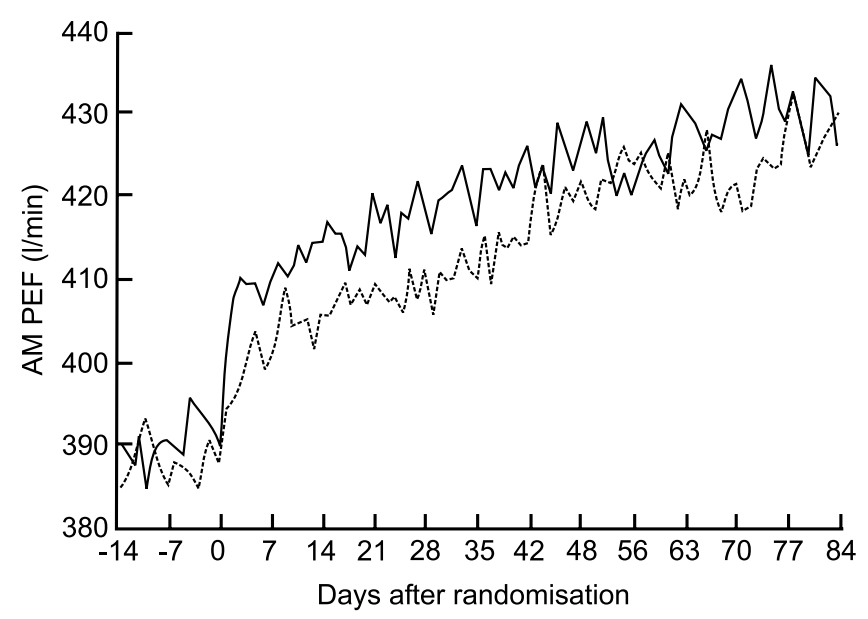

Figure 5

Effect of addition of montelukast $(10 \mathrm{mg} / \mathrm{d})$ or doubling the dose of ICS on morning peak expiratory flow (AM PEF) over 12 week treatment period in patients not adequately controlled by budesonide $800 \mu \mathrm{g} / \mathrm{d}$ (solid line $=$ montelukast + budesonide $800 \mathrm{mg} / \mathrm{d}$, dashed line = budesonide $1600 \mu \mathrm{g} / \mathrm{d}$ ) (with permission from ref 93).

weeks of the run in period (total 4 weeks). Both groups showed progressive improvement in several measures of asthma control compared with baseline. Mean morning PEF improved similarly in the last 10 weeks of treatment compared with baseline in both the montelukast + budesonide group and in the double dose budesonide group (33.5 vs $30.1 \mathrm{~L} / \mathrm{min}$ ). The improvement in montelukast + budesonide group was faster as the mean morning PEF was significantly higher during days 1-3 after start of treatment in this group as compared with the double dose budesonide group (20.1 vs $9.6 \mathrm{~L} / \mathrm{min}$ ) (Figure 5). Both groups showed similar improvements with respect to rescue $\beta_{2}$-agonist use, mean daytime symptom score, nocturnal awakenings, exacerbations, asthma free days, peripheral blood eosinophil counts, and asthma specific quality of life. The authors conclude that addition of montelukast to ICS offers comparable asthma control to doubling the dose of ICS. However, it needs to be remembered that, in most cases, to obtain a statistically significant improvement in asthma control at least a 4fold increase in the dose of ICS is needed (see above).

\section{Montelukast - other literature}

A large $(\mathrm{n}=639)$ study [94] recruited patients with asthma not optimally controlled by ICS (stable dose equivalent to budesonide $400-1600 \mu \mathrm{g} / \mathrm{d}$ ). The patients were required to have $\mathrm{FEV}_{1} \geq 55 \%$, a bronchodilator response greater than $12 \%$, symptoms and rescue $\beta_{2}$ agonist use of at least 1 puff/day. The mean $\mathrm{FEV}_{1}$ at baseline was $81 \%$ predicted. The patients were randomised to obtain either montelukast $(10 \mathrm{mg} / \mathrm{d})$ or placebo in a double-blind manner. The ICS dose remained constant throughout the study. The primary efficacy end point was the percentage of asthma exacerbation days. The major advantage of this study is that this study adopted several different definitions for asthma exacerbation days from previously published other studies, making comparison to other studies more easy. The median percentage of asthma exacerbation days was $35 \%$ lower $(3.1 \%$ vs $4.8 \%$, $\mathrm{p}=0.03$ ) and the median percentage of asthma free days was $56 \%$ higher $(66.1 \%$ vs $42.3 \%, \mathrm{p}=0.001)$ in the montelukast group than in the placebo group. Thus, the NNT with montelukast to avoid one exacerbation day was 13, and the NNT to avoid one day not free of asthma - that is, to gain an asthma free day - was 10. Patients receiving concomitant treatment with montelukast had significantly less $(25.6 \%$ vs $32.2 \%, \mathrm{p}=0.01)$ nocturnal awakenings, and significantly greater reductions in $\beta_{2}$-agonist use $(17.26 \% \mathrm{v} 4.92 \%, \mathrm{p}=0.05$, baseline use was $3.2-3.3$ puffs/day), and morning PEF $(16.86 \mathrm{~L} / \mathrm{min} v s 11.30 \mathrm{~L} /$ $\min , \mathrm{p}=0.05$, baseline $365-373 \mathrm{~L} / \mathrm{min})$. No significant difference was found in asthma specific quality of life or in morning $\mathrm{FEV}_{1}$. The results of this study suggest that although the effect of montelukast on endpoints such as morning PEF, FEV 1 and rescue $\beta_{2}$-agonist use are only small or modest, addition of montelukast may produce a significant improvement of asthma control by reducing the number of asthma exacerbation days.

In another study with patients $(\mathrm{n}=642)$ with symptomatic persistent asthma despite the treatment with BDP $(400 \mu \mathrm{g} / \mathrm{d})$, addition of montelukast $(10 \mu \mathrm{mg} / \mathrm{d})$, improved morning $\mathrm{FEV}_{1}$ and $\mathrm{PEF}$, asthma symptom score and the percentage of asthma exacerbation free days better than placebo during 16 week treatment period [95]. The increase in morning $\mathrm{FEV}_{1}$ was approximately $140 \mathrm{~mL}$ and in morning PEF $10 \mathrm{~L} / \mathrm{min}$. There was a tendency towards reduced rescue medication use with the combination therapy, but the reduction was only 0.2 puffs/day. Addition of montelukast to ICS seemed to prevent the increase in the number of peripheral blood eosinophils seen in other treatment groups.

In an atypical "add-on" study (randomised double-blind, placebo-controlled and crossover trial), addition of montelukast $(10 \mathrm{mg} / \mathrm{d})$ was compared with placebo in patients with asthma $(\mathrm{n}=72)$ and symptoms despite treatment with ICS and additional therapy [96]. Most of the patients used several different types of combination therapy, except leukotriene antagonists, at baseline. The inclusion criteria were defined as "any patient with physician diagnosis of asthma in whom the recruiting physician felt a trial of montelukast was indicated for continued asthma symptoms despite other anti-asthma therapy". A current 
worsening of asthma requiring oral corticosteroid treatment, or worsening in the preceding month were both exclusion criteria, but did not exclude any of those referred for inclusion in the trial. In this setting corresponding to a typical hospital outpatient clinic, addition of montelukast did not result in any significant change in symptom scores, rescue inhaled $\beta_{2}$-agonist use, or morning or evening PEF. When treatment response was defined as a $15 \%$ or greater increase in mean PEF recordings, there were four responders to montelukast and seven responders to placebo. Although several points in this study may be criticised (loose inclusion criteria, small sample size, short 2 week treatment period, no wash-out period, encapsulation of the tablets, exacerbations not analysed as end-point), the results suggest that the effects of montelukast are not as evident in unselected population than in the more clearly defined patients included in other trials [93-95].

The additional anti-inflammatory activity obtained by adding montelukast to the treatment regimen has been assessed in three randomised, double-blind, cross-over studies lasting 10 days-8 weeks. In one study [97], addition of montelukast $(10 \mathrm{mg} / \mathrm{d})$ to salmeterol (50 $\mu \mathrm{g}$ bid) and fluticasone ( $250 \mu \mathrm{g}$ bid) combination was compared with placebo in patients with mild-moderate asthma for 3 weeks. Compared with salmeterol/fluticasone run-in period, adding montelukast was better $(\mathrm{p}<0.05)$ than placebo for inflammatory markers such as AMP-threshold, recovery, exhaled NO, and blood eosinophils but not for lung function. In another study [98], addition of montelukast for 8 weeks to FP ( $100 \mu \mathrm{g}$ bid) was compared with placebo in patients with mild asthma. There were no differences in $\mathrm{FEV}_{1}$ or histamine $\mathrm{PC}_{20}$ between the two treatment regimens. There was no difference in the efficacy of either treatment in decreasing T cell, CD45RO+, mast cell or activated eosinophil numbers in bronchial biopsies. In a third study [99], the addition of montelukast $(10 \mathrm{mg} / \mathrm{d})$ to budesonide $(400 \mu \mathrm{g} / \mathrm{d})$ for 10 days to steroid-naïve patients with asthma was reported not to produce any additional anti-inflammatory benefit when compared with budesonide alone in reducing airway hyperresponsiveness or sputum eosinophilia.

\section{Zafirlukast - other studies}

Addition of high-dose zafirlukast ( $80 \mathrm{mg}$ b.i.d.: 4-fold greater than the approved dose) improved asthma control better than placebo in patients $(n=368)$ on high-dose ICS $(1000-4000 \mu \mathrm{g} / \mathrm{d})$ [100]. Compared with placebo, addition of zafirlukast improved morning and evening PEF and reduced daytime symptom score and rescue medication use [100]. According to a recent meta-analysis $[101,102]$, in symptomatic asthmatic adults, addition of zafirlukast ( $80 \mathrm{mg}$ bid) to ICS did not reduce the risk of an exacerbation requiring systemic steroids after 12 weeks of treatment, compared to double dose ICS [RR = 1.08; 95\% CI $0.47,2.50]$. There were no differences in any other measure of outcome. Higher doses of zafirlukast than currently licensed were associated with increased risk of liver enzyme elevation.

\section{Conclusions on adding a LTRA}

According to recent meta-analyses (12 adult studies and 1 in children) $[101,102]$, leukotriene antagonists (zafirlukast or pranlukast at 2-4 times the licensed dose) combined with ICS (300-2000 $\mu \mathrm{g} / \mathrm{d}$ BDP equivalent) reduce the number of patients with exacerbations that require systemic corticosteroids, compared to ICS alone [RR = $0.34 ; 95 \%$ CI $0.13,0.88]$. This equates to 20 patients (95\% CI 1,100) treated to prevent one needing systemic corticosteroids. There was no difference in side effects $[101,102]$. The addition of licensed doses of LTRA to ICS resulted in a non-significant reduction in the risk of exacerbations requiring systemic steroids (two trials, RR 0.61, $95 \%$ CI $0.36,1.05)$. This systematic review did not include the recent study comparing the addition of montelukast to double-dose ICS [93]. As that systematic review did not include any data of LTRA drugs at currently licensed doses compared with high dose ICS, the author came to a conclusion that the addition of LTRA to ICS may modestly improve asthma control compared with ICS alone but this strategy cannot be recommended as a substitute for increasing the dose of ICS [101]. However, based on one relatively large trial [93], the evidence suggests that addition of montelukast may be equal to doubling the dose of ICS. However, one might criticise this conclusion as this study [93] lacked placebo arm, ie. it is possible that increasing (doubling) the dose of ICS does not produce any real improvement in asthma control as compared with lower ICS dose and thus the result showing non-inferiority to double dose ICS might mean no effect at all. Thus, more data is needed to compare the efficacy of LTRA at currently licensed doses with increasing the dose of ICS.

\section{Adding theophylline Rationale}

Although theophylline has traditionally been classified as a bronchodilator, its ability to control chronic asthma is greater than can be explained by its relatively small degree of bronchodilator activity. In fact, theophylline has immunomodulatory, anti-inflammatory and bronchoprotective effects that may contribute to its efficacy as an anti-asthma drug [103]. There is some evidence that addition of theophylline to ICS treatment improves pulmonary function and asthma symptoms [104], although all studies have not been able to confirm this result [105].

\section{Theophylline - studies included in this systematic review}

The addition of theophylline has been compared with doubling the dose of ICS (BDP and budesonide; $400 \mu \mathrm{g} /$ 
$\mathrm{d} \rightarrow 800 \mu \mathrm{g} / \mathrm{d}$ ) in two separate studies with 195 patients with symptomatic asthma for 6 to 12 weeks $[106,107]$. Theophylline was used at relatively low doses, the mean serum theophylline concentrations were 8.7 and $10.1 \mathrm{mg} /$ $\mathrm{L}$ in these studies.

In the study (Jadad score 4) of Evans and coworkers [106] addition of low-dose theophylline to budesonide (400 $\mu \mathrm{g} / \mathrm{d}$ ) was compared with doubling the dose of budesonide $(800 \mu \mathrm{g} / \mathrm{d})$ in a randomised double-blind trial for 3 months. Patients $(n=62)$ were required to have $F V_{1}$ predicted normal $\geq 50 \%$, bronchodilator response of at least $15 \%$ and to have symptoms despite the use of ICS (equivalent to budesonide dose of $800-1000 \mu \mathrm{g} / \mathrm{d}$ ). The overall treatment effect of addition of theophylline was superior to double-dose budesonide in improving FVC and $\mathrm{FEV}_{1}$ (Figure 6), although at single timepoints there were no significant differences between the treatments. There was no significant difference between the treatments in improving home PEF recordings or reducing $\beta_{2}$-agonist use or symptom scores. There was no difference in the occurrence of possibly drug-related adverse effects between the groups. The statistical power of this study was calculated to detect significant changes over baseline, but not to detect differences (superiority) or non-inferiority between the treatments.

A randomised, double-blind parallel-group study (Jadad score 3) by Ukena and coworkers [107] compared the addition of theophylline to low dose BDP $(400 \mu \mathrm{g} / \mathrm{d})$ with double-dose BDP $(800 \mu \mathrm{g} / \mathrm{d})$ for 6 weeks. Patients (n $=133$ ) were required to have $\mathrm{FEV}_{1} 50-85 \%$ predicted normal and a documented reversibility of at least $15 \%$ of $\mathrm{FEV}_{1}$ over baseline and to be not controlled by BDP (400 $\mu \mathrm{g} / \mathrm{d})$ or equivalent. The sample size of this study was powered to detect equivalence. No significant differences were found between the high-dose BDP and low-dose BDP plus theophylline groups in outcomes such as morning or evening PEF, PEF variability, $\mathrm{FEV}_{1}$, daytime or nighttime symptom scores or rescue medication use. Both treatments were well tolerated.

Lim et al. [108] recruited asthmatic patients that were symptomatic while being treated with low dose inhaled steroids ( $400 \mu \mathrm{g}$ BDP, $200 \mu \mathrm{g}$ FP or $400 \mu \mathrm{g}$ BDP daily). Patients $(n=155)$ were required to have PEF $\geq 50 \%$ of the predicted normal with at least $15 \%$ variability in PEF. The patients were randomised to treatment either with low dose BDP $(400 \mu \mathrm{g} / \mathrm{d})$ alone, theophylline plus BDP (400 $\mu \mathrm{g} / \mathrm{d})$ or high-dose BDP $(1000 \mu \mathrm{g} / \mathrm{d})$ for six months in a double-blind trial (Jadad score 5). No significant differences were found between any of the treatment groups in morning PEF, evening PEF, PEF variability, rescue $\beta_{2}$-agonist use, symptom scores or in the number of exacerbations. Of note is that there were no difference between the low dose BDP alone and high dose BDP groups in any of the parameters. This study was powered to detect superiority of theophylline plus BDP as compared with high-dose BDP. There were no significant differences between the treatment groups for any of the commonly reported adverse effects. The results of this study suggest that when the benefit of an "add-on" therapy is evaluated as compared with double-dose inhaled steroid, additional group using low-dose steroid alone should be included to see whether even the doubling of the dose of steroid produces any benefit to the patient.

\section{Conclusions on the addition of theophylline}

Taken together, the results from two relatively small studies suggest that addition of low-dose theophylline may be equal to doubling the dose of ICS in the treatment of asthma not adequately controlled by low dose of ICS. However, one needs to remember that the effect of doubling the dose of ICS on asthma control is generally small or negligible (see above). Furthermore, a placebo group should be included in these studies to see whether an improvement in asthma control is obtained by doubling the dose of ICS. Thus, more data is needed to confirm the present results. Use of theophylline at concentrations at the lower limit or slightly below the recommended therapeutic range may help to limit the adverse effects.

\section{Comparison between LTRA, theophylline and LABA as add-on options Montelukast versus salmeterol - studies included in this systematic review}

Combination of fluticasone (100 $\mu \mathrm{g}$ bid) and salmeterol ( $50 \mu \mathrm{g}$ bid) in a single inhaler has recently been shown to provide more effective asthma control than montelukast (10 mg daily) combined with FP (100 $\mu$ g bid) in a 12 weeks study (randomised, double-blind, double-dummy, Jadad score 3$)$ in patients $(\mathrm{n}=447)$ whose symptoms were suboptimally controlled by ICS only [109]. The inclusion criteria were $\mathrm{FEV}_{1}$ between $50 \%$ and $80 \%$ predicted normal, and at least 1 additional sign of inadequate asthma control during the 7 preceding days. Salmeterol/ FP combination was superior to montelukast/FP in improving morning PEF (24.9 vs $13.0 \mathrm{~L} / \mathrm{min})$, evening PEF (18.9 vs $9.6 \mathrm{~L} / \mathrm{min}), \mathrm{FEV}_{1}(0.34$ vs $0.20 \mathrm{~L})$ and shortness of breath symptom score $(-0.56 v s-0.40)$ as well as increasing the percentage of days without rescue medication $(26.3 v s$ 19.1\%). In contrast, there was no significant difference in outcomes such as chest tightness, wheeze and overall symptom scores. Asthma exacerbation rates were significantly $(\mathrm{P}=0.031)$ lower in the $\mathrm{FP}+$ salmeterol group $(2 \%)$ than in the $\mathrm{FP}+$ montelukast group $(6 \%)$. Adverse event profiles were reported to be similar.

A similar study [110] comparing the efficacy of combination of FP $(100 \mu \mathrm{g}$ bid $)$ and salmeterol $(50 \mu \mathrm{g}$ bid $)$ in a 


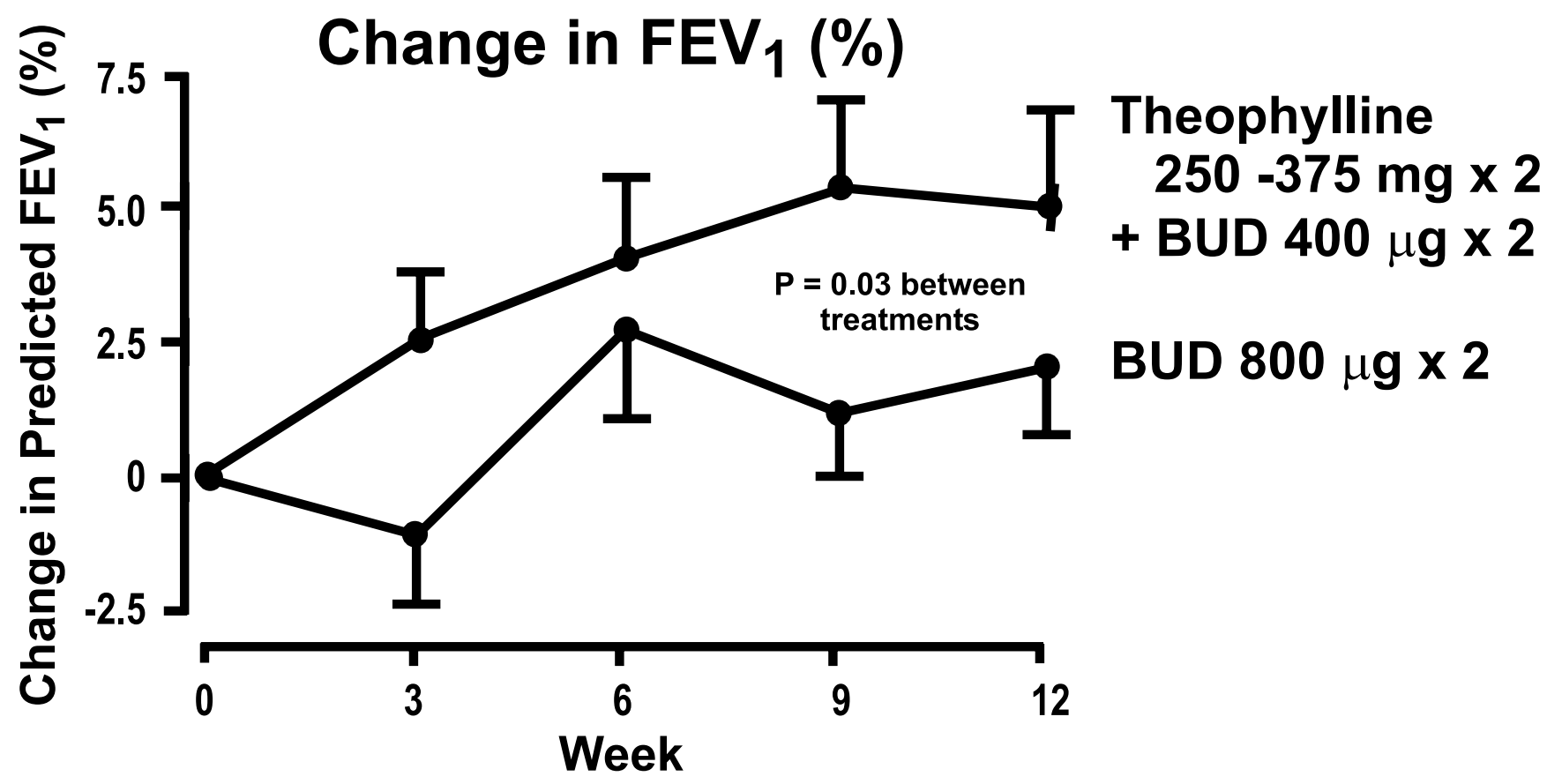

\section{Figure 6}

Mean (+- SE) change in FEV, in $3 \mathrm{I}$ asthma patients treated with high-dose budesonide $(1600 \mu \mathrm{g} / \mathrm{d})$ and $3 \mathrm{I}$ patients given lowdose budesonide $(800 \mu \mathrm{g} / \mathrm{d})$ and theophylline (with permission from ref 106).

single inhaler with combination of montelukast $(10 \mathrm{mg}$ daily) and FP (100 $\mu \mathrm{g}$ bid) in a 12 weeks study (randomised, double-blind, double-dummy, Jadad score 4) in patients $(n=725)$ whose symptoms were suboptimally controlled by ICS (BDP, budesonide, flunisolide 400$1000 \mu \mathrm{g} / \mathrm{d}$ or FP $200-500 \mu \mathrm{g} / \mathrm{day})$ only. The inclusion criteria were $\mathrm{FEV}_{1}$ above $50 \%$ and at least $15 \%$ bronchodilator response, and asthma symptoms at least at 4/7 days during run-in. Salmeterol/FP combination was superior to montelukast/FP in improving morning PEF (36 vs $19 \mathrm{~L} /$ min), evening PEF (29 vs $14 \mathrm{~L} / \mathrm{min}), \mathrm{FEV}_{1}(0.26$ vs $0.17 \mathrm{~L})$, percentage of symptom-free days (42.9 vs $31.5 \%)$, percentage of symptom-free nights (46.5 vs $41.1 \%$ ) as well as increasing the percentage of days without rescue medication (47.9 vs 46\%). In contrast, there was no significant difference in percentage of rescue free nights. The number of patients experiencing at least one asthma exacerbation (any severity) was significantly $(\mathrm{P}<0.05)$ lower in the FP + salmeterol group (9.6\%) than in the FP+ montelukast group $(14.6 \%)$. The percentage of patients who had at least one asthma exacerbation of either moderate or severe intensity was $4.8 \%$ in the salmeterol + FP group and $8.4 \%$ in the montelukast + FP group, but this difference did not reach statistical significance. The time to the first exacerbation was significantly $(P<0.05)$ longer in the salmeterol + FP group than in the montelukast + FP group. Adverse event profiles were reported to be similar.

Another very similar study [111] was designed to demonstrate the non-inferiority of combination of montelukast (10 mg daily) and FP (100 $\mu \mathrm{g}$ bid in dry powder inhaler) as compared with combination of FP $(100 \mu \mathrm{g}$ bid in dry powder inhaler) and salmeterol (50 $\mu \mathrm{g}$ bid; metered dose inhaler) on asthma exacerbations. This 48 weeks study (randomised, double-blind, double-dummy, Jadad score $5)$ included patients $(n=1490)$ whose symptoms were suboptimally controlled by ICS (equivalent to BDP 200$1000 \mu \mathrm{g} / \mathrm{d})$. The inclusion criteria were $\mathrm{FEV}_{1}$ 50-90\% predicted and at least $12 \%$ bronchodilator response, shortacting $\beta_{2}$-agonist use of one puff/day or more and asthma symptoms. Salmeterol/FP combination was superior to montelukast/FP in improving morning PEF (34.6 vs 17.7 $\mathrm{L} / \mathrm{min}), \mathrm{FEV}_{1}(0.19$ vs $0.11 \mathrm{~L})$. In contrast, there was no significant difference in nocturnal awakenings and asthma specific quality of life score. The percentage of patients experiencing at least one asthma exacerbation (any severity) was shown to be similar in the FP + salmeterol group (19.1\%) than in the $\mathrm{FP}+$ montelukast group $(20.1 \%)$. Also there was no difference in the time to the first exacerbation between the salmeterol + FP and the montelukast + FP groups. Peripheral blood eosinophils 
were reported to be reduced significantly more in the montelukast + FP group $\left(-0.04 \times 10^{3} / \mu \mathrm{l}\right)$ than in the salmeterol + FP group $\left(-0.01 \times 10^{3} / \mu \mathrm{l}\right)$. Interestingly more serious adverse events were reported in the salmeterol + FP group.

In another randomised, double-blind, double-dummy, parallel-group study (Jadad score 3$)$ in patients $(\mathrm{n}=948)$ with symptomatic asthma despite treatment with ICS, addition of montelukast (10 mg daily) was compared with addition of salmeterol ( $50 \mu \mathrm{g}$ bid) for 12 weeks [112]. Patients were required to have symptoms despite the constant dose of ICS (any brand at any dose) and FEV $_{1}$ between $50 \%$ and $80 \%$ predicted and at least $12 \%$ bronchodilator response. Treatment with salmeterol resulted in significantly greater improvements from baseline compared with montelukast for most efficacy measurements, including morning PEF (35.0 vs $21.7 \mathrm{~L} / \mathrm{min}$ ), percentage of symptom-free days (24 v 16\%) and percentage of rescue-free days (27 vs 20\%). Also total supplemental salbutamol use (-1.90 vs -1.66 puffs per day) and nighttime awakenings per week (-1.42 vs -1.32) decreased significantly more with salmeterol than with montelukast. Six percent of patients in the salmeterol group experienced a total of 27 asthma exacerbations compared with 5\% of patients in the montelukast group who experienced 24 asthma exacerbations during the 12 weeks treatment period. However, the patients experiencing an asthma exacerbation were withdrawn from the study. Thus, annualised incidences of exacerbations cannot be compared [112]. The safety profiles of the two treatments were reported to be similar.

Taken together, addition of salmeterol seems to produce better improvement of asthma control when lung function is assessed than addition of montelukast in patients with asthma suboptimally controlled by small to moderate doses of ICS. However, in one long-term study [111] addition of montelukast to fluticasone was shown to be non-inferior to addition of salmeterol when the percentage of patients with at least one asthma exacerbation was used as the primary endpoint. Whereas addition of salmeterol may produce a better improvement in lung function, addition of montelukast may provide additional anti-inflammatory efficacy to ICS that is reflected in a long-term efficacy on asthma exacerbations. A factor that may produce a selection bias in these studies [109-111] is that a positive response to bronchodilator was required for inclusion. In fact, the reported mean improvements in $\mathrm{FEV}_{1}$ in response to $\beta_{2}$-agonist were $23-24 \%$ [109], 27.0$27.4 \%$ [110] and $18.4-18.8 \%$ [111] in the single studies. This may produce a selection bias favouring long-acting $\beta_{2}$-agonist. However, one needs to remember that many of those studies done with leukotriene receptor antagonist to prove their efficacy in the treatment of asthma have been performed with patients displaying a significant response to $\beta_{2}$-agonist. Another factor that might be considered to produce bias is that all the above three studies that report salmeterol to be better have been sponsored by the producer of salmeterol and that study reporting the non-inferiority of montelukast as compared with salmeterol has been sponsored by producer of montelukast.

\section{Montelukast versus salmeterol - other literature}

In addition to the normal clinical endpoints, the effects of addition of salmeterol ( $50 \mu \mathrm{g}$ bid) or montelukast (10 $\mathrm{mg} / \mathrm{d}$ ) to the treatment regimen were analysed on AMP bronchial challenge, blood eosinophil counts and exhaled NO in a placebo-controlled, double-dummy, crossover study in patients $(n=20)$ with persistent asthma not controlled with ICS [113]. For the provocative concentration of AMP causing a $20 \%$ fall in $\mathrm{FEV}_{1}$, compared to placebo, there were significant differences with the first and last doses of montelukast as well as the first but not the last dose of salmeterol, thus indicating the development of some tolerance with salmeterol. Only montelukast produced a significant, albeit trivial, suppression of blood eosinophil count. There were significant improvements with the first doses of salmeterol for all parameters of lung function. After 2 weeks of treatment, there were significant improvements with both drugs on rescue bronchodilator requirement and morning PEF. There were no significant differences between drugs for any endpoints except blood eosinophils. Thus, the results suggest some anti-inflammatory activity for montelukast when used as an "add-on" therapy.

\section{Salmeterol versus zafirlukast - studies included in this systematic review}

In a randomised, double-blind, double-dummy parallelgroup trial (Jadad score 3 ) addition of zafirlukast (20 mg bid) was compared with the addition of salmeterol ( $50 \mu \mathrm{g}$ bid via MDI) for 4 weeks in adult and adolescent patients ( $n=429)$ with persistent asthma [114]. Patients were required to have $\mathrm{FEV}_{1}$ percentage predicted normal between 50 and $70 \%$ with or without asthma symptoms, or $\mathrm{FEV}_{1}$ of $70.1 \%$ to $80 \%$ of predicted normal values and symptoms or requirement for rescue $\beta_{2}$-agonist use $\geq 4$ puffs/day or diurnal PEF-variation of more than $20 \%$ at two days during 6 days run-in. Both inhaled salmeterol and oral zafirlukast resulted in within-group improvements from baseline in measures of pulmonary function (morning and evening PEF and $\mathrm{FEV}_{1}$ ), asthma symptoms, and supplemental salbutamol use. Salmeterol treatment resulted in significantly greater improvements from baseline compared with zafirlukast for most efficacy measurements, including morning PEF (28.8 vs $13.0 \mathrm{~L} /$ min), evening PEF (21.8 vs $11.2 \mathrm{~L} / \mathrm{min})$, combined patient-rated symptom scores for all symptoms (-35 vs $21 \%$ ), daytime albuterol use (41 vs 25\%) and night-time 
salbutamol use ( $42 \%$ vs $16 \%)$. Also, statistically significant differences favouring the addition of salmeterol were noted on patient-rated symptom scores for shortness of breath and chest tightness, percentage of symptom-free days, sleep symptoms, nighttime awakenings and percentage of days and nights with no albuterol use. There was no difference between the groups in symptom score for wheezing. Interestingly, the difference between salmeterol and zafirlukast was clear at week 1 , but not at 4 weeks when the effect on $\mathrm{FEV}_{1}$ was analysed. One factor that may affect the results of this study is that there may be a randomisation bias as the proportions of patients using FP or TAA were not similar in the salmeterol and zafirlukast groups. This study was funded by the producer of salmeterol.

\section{Salmeterol versus zafirlukast - other literature}

As a part of the above study [114], a randomised, doubleblind, double-dummy parallel-group trial comparing the addition of zafirlukast ( $20 \mathrm{mg}$ b.i.d) with the addition of salmeterol $(50 \mu \mathrm{g}$ bid $)$ for 4 weeks in patients $(\mathrm{n}=289)$ with persistent asthma, $80 \%$ of whom were on a concurrent ICS regimen has been published [115]. Both inhaled salmeterol and oral zafirlukast resulted in within-group improvements from baseline in measures of pulmonary function (morning and evening PEF and $\mathrm{FEV}_{1}$ ), asthma symptoms, and supplemental salbutamol use. Salmeterol treatment resulted in significantly greater improvements from baseline compared with zafirlukast for most efficacy measurements, including morning PEF (29.6 vs $13.0 \mathrm{~L} /$ $\mathrm{min})$, percentage of symptom-free days $(22.2 \%$ vs $8.8 \%)$ and percentage of days and nights with no supplemental albuterol use (30.5\% vs. $11.3 \%)$.

\section{Formoterol versus zafirlukast versus theophylline - other literature}

An open, randomised Turkish study [116] recruited patients with moderate persistent asthma having symptoms despite the use of moderate to high doses of ICS. The patients were required to have a $\mathrm{FEV}_{1}$ reversibility of at least $15 \%$. Patients $(n=64)$ were randomised to three different treatments budesonide $(800 \mu \mathrm{g} / \mathrm{d})$ plus formoterol (9 $\mu \mathrm{g}$ bid), budesonide $(800 \mu \mathrm{g} / \mathrm{d}$ ) plus zafirlukast $(20 \mathrm{mg}$ bid) or budesonide $(800 \mu \mathrm{g} / \mathrm{d})$ plus sustained-release theophylline $(400 \mathrm{mg} / \mathrm{d})$ for three months. After three months there were no between group differences in endpoints such as morning and evening PEF, PEF variability, $\mathrm{FEV}_{1}$, daytime or nighttime symptom scores and rescue terbutaline use. However, the addition of formoterol produced earlier improvements compared with the two other groups in criteria such as PEF variability, day- and nighttime asthma symptom scores and supplemental terbutaline use. Patients in budesonide plus zafirlukast group experienced most adverse effects, but no statistical analysis was presented. The authors conclude that in patients who still have symptoms despite the treatment with ICS, the addition of any of these medications to the treatment is a logical approach and may be chosen.

\section{Conclusions on the comparisons between LABA, LTRA and theophylline as add-on options}

LABA (salmeterol) seem to have superior efficacy as addon therapy in persistent asthma not controlled by low to moderate doses of ICS as compared with LTRA (montelukast; four studies or zafirlukast; one study). More studies comparing the different add-on options are needed as well as studies with longer duration as the current evidence is mostly limited to follow-up period of 3 months.

\section{Compliance and treatment strategies}

When assessing a patient with persistent asthma who is not adequately controlled by low to moderate doses of ICS:

- It is important to find out whether the patient is using the prescribed medication correctly. Poor compliance in asthma patients treated with ICS is a very common reason for treatment failure. Compliance with ICS is often less than $50 \%[117,118]$. Oral asthma therapies may result in better compliance [119].

- Secondly, it is important to check whether the inhalation technique is adequate. Problems with the inhalation techniques are very common, especially among children and the elderly [120]. Good patient education, especially if it is self-management oriented improves health outcomes in adults with asthma [121].

- Thirdly, it is important to search for possible environmental factors, such as changes in home and working environment, hobbies and pets.

If asthma exacerbations are the dominant problem, guided self-management of asthma has been proven to be an efficient treatment strategy. In a Cochrane review [121] self-management of asthma was compared with usual care in 22 studies. Self-management reduced hospital admissions (odds ratio; OR 0.58, 95\% confidence interval; CI 0.38 to 0.88 ), emergency room visits (OR $0.71 ; 95 \%$ CI $0.57-0.90)$, unscheduled visits to the doctor (OR 0.57; $95 \%$ CI 0.40 to 0.82 ), days off from work or school (OR $0.55 ; 95 \%$ CI 0.38 to 0.79 ) and nocturnal asthma (OR $0.53 ; 95 \%$ CI 0.39 to 0.72 ).

\section{Conclusions}

Addition of formoterol or salmeterol seems to be superior as compared with the increase in the dose of the ICS in improving lung function, controlling asthma symptoms and reducing the use of rescue bronchodilator treatment. By increasing (doubling) the dose of the ICS the clinical 
improvement is likely to be of small magnitude. However, if frequent exacerbations are the major problem, increasing the dose of ICS may significantly help to reduce the number of exacerbations. By avoiding doses above 1000 $1500 \mu \mathrm{g} / \mathrm{d}$ (budesonide and BDP) or $500-750 \mu \mathrm{g} / \mathrm{d}$ (FP) the risk of systemic adverse effects remains low. However, it should be noted that the evidence on the superiority of LABA is limited to symptomatic patients with mild to severe persistent asthma currently treated with low to moderate doses of ICS and presenting with a significant bronchodilator response. Also, addition of the LTRA montelukast or zafirlukast may improve asthma control in patients remaining symptomatic with ICS and addition of montelukast may be equal to double-dose ICS. Addition of LABA (salmeterol) seems to produce better asthma control as compared with a LTRA (montelukast or zafirlukast) whereas the long-term efficacy of LTRA (montelukast) on asthma exacerbations may be equal to LABA (salmeterol). There is evidence that addition of low-dose theophylline to the treatment regimen may be equal to doubling of the dose of ICS. However, more studies are needed to better clarify the role of leukotriene antagonists and theophylline as "add on"-therapies. For patients with inappropriate inhalation technique the value of LTRA or theophylline are especially worth considering. More studies are now needed to compare between different add-on therapies and to explore the effect of more than one addon therapy in patients with more severe asthma as well as in those having symptoms but not significant bronchodilator response.

Another issue not addressed by these studies of large patient groups are the different responses of patients to the different add-on therapies. This needs to be studied by comparing add-on treatments in the same patients, but these studies are difficult and prolonged. In the future it may be possible to predict factors that predict the value of a particular add-on therapy in a particular patient, but the currently published studies unfortunately provide no guidance.

\section{Abbreviations}

ACTH: corticotrophin, AMP: adenosine monophosphate, AQLQ: asthma quality of life questionnaire, BAL: bronchoalveolar lavage, BDP: beclomethasone dipropionate, ECP: eosinophil cationic protein, $\mathrm{FEF}_{50}$ : forced expiratory flow when $50 \%$ of vital capacity has been exhaled, FENO: exhaled nitric oxide, $\mathrm{FEV}_{1}$ : forced expiratory volume in one second, FP: fluticasone propionate, FVC: forced vital capacity, HFA: hydrofluoroalkane-134a formulation, HPA: hypothalamic-pituitary-adrenal, ICS: inhaled corticosteroid, LABA: long-acting $\beta_{2}$-agonist, LTRA: leukotriene receptor antagonist, MDI: metered dose inhaler, NNH: number needed to harm, NNT: number needed to treat, $\mathrm{PC}_{20}$ : provocative concentration causing a $20 \%$ fall in $\mathrm{FEV}_{1}, \mathrm{PD}_{20}$ : provocative dose causing a $20 \%$ fall in FEV $_{1}$, PEF: peak expiratory flow, TAA: triamcinolone acetonide

\section{Authors' contributions}

HK carried out the literature searches, evaluated the studies, conceived the review and drafted the manuscript. AL, EM and PJB participated in the design and writing of the review. All authors read and approved the final manuscript.

\section{Additional material}

\section{Additional File 1}

Tables 1-7-Kankaanranta.doc contains tables 1-7 of this review. Click here for file

[http://www.biomedcentral.com/content/supplementary/14659921-5-17-S1.doc]

\section{Acknowledgements}

Production of this review was supported by Tampere Tuberculosis Foundation (Finland), the Finnish Anti-Tuberculosis Association Foundation, Jalmari and Rauha Ahokas Foundation (Finland), the Academy of Finland and the Medical Research Fund of Tampere University Hospital (Finland). No support was obtained from the pharmaceutical industry.

\section{References}

I. NHLBI. National Asthma Education and Prevention Program, Expert Panel Report 2: Guidelines for the diagnosis and management of asthma. In NIH Publication No. 97-405 I Bethesda, MD: US Department of Health and Human Services; 1997.

2. NHLBI. Global Initiative for Asthma: Global strategy for astma management and prevention. NIH Publication No 02-3659 2002.

3. Barnes PJ, Pedersen S, Busse WW: Efficacy and safety of inhaled corticosteroids. New developments. Am J Respir Crit Care Med 1998, 157:SI-S53.

4. Martin RJ, Szefler SJ, Chincilli VM, Kraft M, Dolovich M, Boushey HA, Cherniak RM, Craig T], Drazen JM, Fagan JK, Fahy JV, Fish JE, Ford JG, Israel E, Kunselman SJ, Lazarus SC, Lemanske RF Jr, Peters SP, Sorkness CA: Systemic effect comparisons of six inhaled corticosteroid preparations. Am J Respir Crit Care Med 2002, 165:1377-1383.

5. The British Thoracic Society: The British guidelines on asthma management 1995 review and position statement. Thorax 1997, 52(SuppI I):SI-S20.

6. NHLBI. Global Initiative for Asthma: Global strategy for asthma management and prevention. NHLBI/WHO Workshop Report. NIH publication no. 95-3659 1995.

7. Lipworth BJ, Jackson CM: Second-line controller therapy for persistent asthma uncontrolled on inhaled corticosteroids. The step 3 dilemma. Drugs 2002, 62:23 15-2332.

8. Masoli M, Holt S, Beasley R: What to do at step 3 asthma guidelines - increase the dose of inhaled corticosteroids or add a long-acting $\beta$-agonist drug. I Allergy Clin Immunol 2003, I I 2: I 0- I I.

9. Holt S, Suder A, Weatherall M, Cheng S, Shirtcliffe P, Beasley R: Dose-response relation of inhaled fluticasone propionate in adolescents and adults with asthma: meta-analysis. BMJ 200I, 323:253-256

10. Adams N, Bestall J, Jones P: Inhaled beclomethasone at different doses for long-term asthma (Cochrane Review). In In: The Cochrane Library Issue 3 Oxford:Update Software; 200I.

II. Adams N, Bestall J, Jones PW: Inhaled fluticasone propionate for chronic asthma (Cochrane Review). In In: The Cochrane Library Issue 3 Oxford:Update Software; 200I. 
12. Adams N, Bestall J, Jones P: Inhaled budesonide at different doses for chronic asthma (Cochrane Review). In In: The Cochrane Library Issue I Oxford:Update Software; 2002.

13. Shrewsbury S, Pyke S, Britton M: Meta-analysis of increased dose of inhaled steroid or addition of salmeterol in symptomatic asthma (MIASMA). BMJ 2000, 320: I 368-I373.

14. Bousquet J, Ben-Joseph R, Messonnier M, Alemao E, Gould AL: A meta-analysis of the dose-response relationship of inhaled corticosteroids in adolescents and adults with mild to moderate persistent asthma. Clin Ther 2002, 24: I-20.

15. Heyneman CA, Crafts R, Holland J, Arnold AD: Fluticasone versus salmeterol/low-dose fluticasone for long-term asthma control. Ann Pharmacother 2002, 36: 1944-1949.

16. Powell H, Gibson PG: Inhaled corticosteroid doses in asthma: an evidence-based approach. Med J Austral 2003, I 78:223-225.

17. Jadad AR, Moore RA, Carroll D, Jenkinson C, Reynolds DJM, Gavaghan DJ, McQuay $H$ J: Assessing the quality of reports of randomized clinical trials: is blinding necessary. Controlled Clin Trials 1996, I 7:1-12.

18. Busse WW, Brazinsky S, Jacobson K, Stricker W, Schmitt K, Vanden Burgt J, Donnell D, Hannon S, Colice GL: Efficacy response of inhaled beclomethasone dipropionate in asthma is proportional to dose and is improved by formulation with a new propellant. J Allergy Clin Immunol 1999, I 04: I21 5- I 222.

19. Miyamoto T, Takahashi T, Nakajima S, Makino S, Yamakido M, Mano K, Nakashima M, Tollemar U, Selroos O: A double-blind, placebocontrolled dose-response study with budesonide Turbuhaler in Japanese asthma patients. Japanese Pulmicort Turbuhaler study group. Respirology 2000, 5:247-256.

20. Dahl R, Lundback B, Malo JL, Mazza JA, Nieminen MM, Saarelainen P, Barnacle $\mathrm{H}$ : A dose-ranging study of fluticasone propionate in adult patients with moderate asthma. International Study Group. Chest 1993, I04:1352-1358.

21. Chervinsky $P$, van As A, Bronsky EA, Dockhorn R, Noonan M, LaForce C, Pleskow W: Fluticasone propionate aerosol for the treatment of adults with mild to moderate asthma. J Allergy Clin Immunol I 994, 94:676-683.

22. Pearlman DS, Noonan MJ, Tashkin DP, Goldstein MF, Hamedani AG, Kellerman DJ, Schaberg A: Comparative efficacy and safety of twice daily fluticasone propionate powder versus placebo in the treatment of moderate asthma. Ann Allergy Asthma Immunol 1997, 78:356-362

23. Sheffer AL, LaForce C, Chervinsky P, Pearlman D, Schaberg A, the fluticasone propionate asthma study group: Fluticasone propionate aerosol: efficacy in patients with mild to moderate asthma. J Fam Pract 1996, 42:369-375.

24. Wasserman SI, Gross GN, Schoenwetter WF, Munk ZM, Kral KM, Kellerman DJ: A I2-week dose-ranging study of fluticasone propionate powder in the treatment of asthma. J Asthma 1996, 33:265-274.

25. Wolfe JD, Selner JC, Mendelson LM, Hampel F, Schaberg A: Effectiveness of fluticasone propionate in patients with moderate asthma: a dose-ranging study. Clin Ther 1996, 18:635-646.

26. Nathan RA, Li JT, Finn A, Jones R, Payne JE, Wolford JP, Harding SM: A dose-ranging study of fluticasone propionate administered once daily via multidose powder inhaler to patients with moderate asthma. Chest 2000, I I 8:296-302.

27. Bernstein DI, Berkowitz RB, Chervinsky P, Dvorin DJ, Finn AF, Gross GN, Karetzky M, Kemp JP, LaForce C, Lumry W, Mendelson LM, Nelson H, Pearlman D, Rachelefsky G, Ratner P, Repsher L, Segal AT, Selner JC, Settipane GA, Wanderer A, Cuss FM, Nolop KB, Harrison JE: Dose-ranging study of a new steroid for asthma: mometasone furoate dry powder inhaler. Respir Med 1999, 93:603-6I2.

28. Bousquet J, D'Urzo AD, Hedlin G, Barraza CH, Boulet LP, SuarezChacon R, Harnest U, Lundback B, Martinez Morales G, Nieminen MM, Nolop KB, Visser S, Lutsky BN: Comparison of the efficacy and safety of mometasone furoate dry powder inhaler to budesonide Turbuhaler. Eur Respir J 2000, I 6:808-8I6.

29. O'Connor B, Bonnaud G, Haahtela T, Luna JM, Querfurt H, Wegener $\mathrm{T}$, Lutsky BN: Dose-ranging study of mometasone furoate dry powder inhaler in the treatment of moderate persistent asthma using fluticasone propionate as an active comparator. Ann Allergy Asthma Immunol 2001, 86:397-404.

30. Welch MJ, Levy S, Smith JA, Feiss G, Farrar JR: Dose-ranging study of the clinical efficacy of twice-daily triamcinolone acetonide inhalation aerosol in moderately severe asthma. Chest 1997, I | 2:597-606.

31. Welch M, Bernstein D, Gross G, Kane RE, Banerji D: A controlled trial of chlorofluorocarbon-free triamcinolone acetonide inhalation aerosol in the treatment of adult patients with persistent asthma. Azmacort HFA Study Group. Chest 1999, I | 6: | 304-13|2.

32. Adams N, Bestall JM, Jones PW: Inhaled fluticasone at different doses for chronic asthma (Cochrane Review). In In The Cochrane Library Issue I Oxford:Update Software; 2003.

33. Busse WW, Chervinsky P, Condemi J, Lumry WR, Petty TL, Rennard $S$, Townley RG: Budesonide delivered by Turbuhaler is effective in a dose-dependent fashion when used in the treatment of adult patients with chronic asthma. J Allergy Clin Immunol 1998, I $01: 457-463$

34. Santanello NC, Zhang J, Seidenberg B, Reiss TF, Barber BL: What are minimal important changes for asthma measures in a clinical trial? Eur Respir J 1999, 14:23-27.

35. Crim C, Pierre LN, Daley-Yates PT: A review of the pharmacology and pharmacokinetics of inhaled fluticasone propionate and mometasone furoate. Clin Ther 2001, 23:1339-1354.

36. Chervinsky P, Nelson HS, Bernstein DI, Berkowitz RA, Siegel SC: Comparison of mometasone furoate administered by metered dose inhaler with beclomethasone dipropionate. Int J Clin Pract 2002, 56:419-425.

37. Jacobson K, Chervinsky P, Noonan M, Kane RE, Banerji D, Uryniak T. Placebo-controlled, comparative study of the efficacy and safety of triamcinolone acetonide inhalation aerosol with the non-CFC propellant HFA-I34a in patients with asthma. Azmacort HFA Clinical Study Group. Ann Allergy Asthma Immunol 1999, 83:327-333.

38. Wilson AM, Lipworth BJ: Dose-response evaluation of the therapeutic index for inhaled budesonide in patients with mildto-moderate asthma. Am J Med 2000, I 08:269-275.

39. Nielsen LP, Dahl R: Therapeutic ratio of inhaled corticosteroids in adult asthma. A dose-range comparison between fluticasone propionate and budesonide, measuring their effect on bronchial hyperresponsiveness and adrenal cortex function. Am J Respir Crit Care Med 2000, I 62:2053-2057.

40. Swystun VA, Bhagat R, Kalra S, Jennings B, Cockcroft DW: Comparison of 3 different doses of budesonide and placebo on the early asthmatic response to inhaled allergen. J Allergy Clin Immunol 1998, 102:363-367.

4I. Toogood JH, White FA, Baskerville JC, Fraher LJ, Jennings B: Comparison of the antiasthmatic, oropharyngeal, and systemic glucocorticoid effects of budesonide administered through a pressurized aerosol plus spacer or the Turbuhaler dry powder inhaler. J Allergy Clin Immunol I997, 99:186-193.

42. Jatakanon A, Kharitonov S, Lim S, Barnes PJ: Effect of differing doses of inhaled budesonide on markers of airway inflammation in patients with mild asthma. Thorax 1999, 54:108-II4.

43. Taylor DA, Jensen MW, Kanabar V, Engelstatter R, Steinijans VW, Barnes PJ, O'Connor B]: A dose-dependent effect of the novel inhaled corticosteroid ciclesonide on airway responsiveness to adenosine-5'-monophosphate in asthmatic patients. Am J Respir Crit Care Med 1999, 160:237-243.

44. Silkoff PE, McClean P, Spino M, Erlich L, Slutsky AS, Zamel N: Doseresponse relationship and reproducibility of the fall in exhaled nitric oxide after inhaled beclomethasone dipropionate therapy in asthma patients. Chest 200 I, I I 9:1322- I328.

45. Jones SL, Herbison P, Cowan JO, Flannery EM, Hancox RJ, McLachlan CR, Taylor DR: Exhaled NO and assessment of anti-inflammatory effects of inhaled steroid: dose-response relationship. Eur Respir J 2002, 20:601-608.

46. Inman MD, Watson RM, Rerecich T, Gauvreau GM, Lutsky BN, Stryszak P, O'Byrne PM: Dose-dependent effects of inhaled mometasone furoate on airway function and inflammation after allergen inhalation challenge. Am J Respir Crit Care Med 2001, 1 64:569-574.

47. Lipworth BJ: Systemic adverse effects of inhaled corticosteroid therapy: A systematic review and meta-analysis. Arch Intern Med 1999, I 59:941-955.

48. Harrison LI, Colice GL, Donnell D, Soria I, Dockhorn R: Adrenal effects and pharmacokinetics of CFC-free beclomethasone dipropionate: a I4-day dose-response study. J Pharm Pharmacol 1999, 5 |:263-269. 
49. McCubbin MM, Milavetz G, Grandgeorge S, Weinberger M, Ahrens R, Sargent C, Vaughan LM: A bioassay for topical and systemic effect of three inhaled corticosteroids. Clin Pharmacol Ther 1995, 57:455-460.

50. Wilson AM, Brewster HJ, Lipworth BJ: Dose-response comparison of systemic bioactivity with inhaled budesonide and triamcinolone acetonide in asthmatic adults. J Allergy Clin Immunol 1998, 102:751-756.

51. Wilson AM, McFarlane LC, Lipworth BJ: Dose-response effect for adrenal suppression with repeated twice daily inhaled fluticasone propionate and triamcinolone acetonide in adult asthmatics. Am J Respir Crit Care Med I 997, I 56: I 274-I 277.

52. Clark DJ, Grove A, Cargill RI, Lipworth BJ: Comparative adrenal suppression with inhaled budesonide and fluticasone propionate in adult asthmatic patients. Thorax 1996, 5 I:262-266.

53. Clark DJ, Lipworth BJ: Evaluation of corticotropin releasing factor stimulation and basal markers of hypothalamic-pituitaryadrenal axis suppression in asthmatic patients. Chest 1997, I I 2: I 248-1252.

54. Wilson AM, Lipworth B]: Short-term dose-response relationships for the relative systemic effects of oral prednisolone and inhaled fluticasone in asthmatic adults. $\mathrm{Br} J$ Clin Pharmacol 1999, 48:579-585.

55. Wilson AM, Sims EJ, Lipworth BJ: Dose response with fluticasone propionate on adrenocortical activity and recovery of basal and stimulated responses after stopping treatment. Clin Endocrinol (Oxf) 1999, 50:329-335.

56. Altman LC, Findlay SR, Lopez M, Lukacsko P, Morris RJ, Pinnas JL, Ratner $\mathrm{PH}$, Szefler SJ, Welch MJ: Adrenal function in adult asthmatics during long-term daily treatment with 800, I,200, and I,600 micrograms triamcinolone acetonide. Multicenter study. Chest 1992, I0 I:1250-1256.

57. Grahnen A, Eckernäs S-Å, Brundin RM, Ling-Andersson A: An assessment of the systemic activity of single doses of inhaled fluticasone propionate in healthy volunteers. $\mathrm{Br}$ J Clin Pharmacol 1994, 38:52|-525.

58. Donnelly R, Williams KM, Baker AB, Badcock C-A, Day RO, Seale JP: Effects of budesonide and fluticasone on 24-hour plasma cortisol. A dose-response study. Am J Respir Crit Care Med 1997, | 56: |746-|75I.

59. Derom E, Van Schoor J, Verhaeghe W, Vincken W, Pauwels R: Systemic effects of inhaled fluticasone propionate and budesonide in adult patients with asthma. Am J Respir Crit Care Med 1999, 160:|57-16I.

60. Brutsche MH, Brutsche IC, Munawar M, Langley SI, Masterson CM Daley-Yates PT, Brown R, Custovic A, Woodcock A: Comparison of pharmacokinetics and systemic effects of inhaled fluticasone propionate in patients with asthma and healthy volunteers: a randomised crossover study. Lancet 2000, 356:556-56I.

61. Harrison TW, Wisniewski A, Honour J, Tattersfield AE: Comparison of the systemic effects of fluticasone propionate and budesonide given by dry powder inhaler in healthy and asthmatic subjects. Thorax 2001, 56:186-191.

62. Jarvis B, Faulds D: Inhaled fluticasone propionate. A review of its therapeutic efficacy at dosages $<500 \mu \mathrm{g} / \mathrm{d}$ in adults and adolescents with mild to moderate asthma. Drugs 1999 57:769-803

63. Barnes PJ: Effect of $\beta$-agonists on inflammatory cells. J Allergy Clin Immunol 1999, 104:S10-S17.

64. Baraniuk JN, Ali M, Brody D, Maniscalco J, Gaumond E, Fitzgerald T, Wong G, Yuta A, Mak JC, Barnes PJ, Bascom R, Troost T: Glucocorticoids induce $\beta_{2}$-adrenergic receptor function in human nasal mucosa. Am J Respir Crit Care Med 1997, I 55:704-7I0.

65. Eickelberg $O$, Roth M, Lorx R, Bruce $V$, Rudiger J, Johnson M, Block $\mathrm{LH}$ : Ligand-independent activation of the glucocorticoid receptor by $\beta_{2}$-adrenergic receptor agonists in primary human lung fibroblasts and vascular smooth muscle cells. J Biol Chem 1999, 274: 1005-1010.

66. Barnes PJ: Scientific rationale for inhaled combination therapy with long-acting $\beta_{\mathbf{2}}$-agonists and corticosteroids. Eur Respir J 2002, 19:182-191.

67. Pauwels RA, Lofdahl CG, Postma DS, Tattersfield AE, O'Byrne P, Barnes PJ, Ullman A: Effect of inhaled formoterol and budesonide on exacerbations of asthma. Formoterol and Corticosteroids Establishing Therapy (FACET) International Study Group. N Engl J Med 1997, 337:|405-I4II.
68. O'Byrne PM, Barnes PJ, Rodriguez-Roisin R, Runnerstrom E, Sandstrom T, Svensson K, Tattersfield A: Low dose inhaled budesonide and formoterol in mild persistent asthma. The OPTIMA randomized trial. Am J Respir Crit Care Med 200I, I 64: I 392-1397.

69. Lalloo UG, Malolepszy J, Kozma D, Krofta K, Ankerst J, Johansen B, Thomson NC: Budesonide and formoterol in a single inhaler improves asthma control compared with increasing the dose of corticosteroid in adults with mild-to-moderate asthma. Chest 2003, I 23: | 480- | 487.

70. Greening AP, Ind PW, Northfield M, Shaw G: Added salmeterol versus higher-dose corticosteroid in asthma patients with symptoms on existing inhaled corticosteroid. Allen \& Hanburys Limited UK Study Group. Lancet 1994, 344:2 19-224.

7I. Woolcock A, Lundback B, Ringdal N, Jacques LA: Comparison of addition of salmeterol to inhaled steroids with doubling of the dose of inhaled steroids. Am J Respir Crit Care Med 1996, | 53: | 48|-|488.

72. Baraniuk J, Murray JJ, Nathan RA, Berger WE, Johnson M, Edwards LD, Srebro S, Rickard KA: Fluticasone alone or in combination with salmeterol vs triamcinolone in asthma. Chest 1999 , I | 6:625-632.

73. Condemi J], Goldstein S, Kalberg C, Yancey S, Emmett A, Rickard K: The addition of salmeterol to fluticasone propionate versus increasing the dose of fluticasone propionate in patients with persistent asthma. Salmeterol Study Group. Ann Allergy Asthma Immunol 1999, 82:383-389.

74. Kelsen SG, Church NL, Gillman SA, Lanier BQ, Emmett AH, Rickard $\mathrm{KA}$, Anderson $\mathrm{WH}$ : Salmeterol added to inhaled corticosteroid therapy is superior to doubling the dose of inhaled corticosteroids: a randomized clinical trial. J Asthma 1999, 36:703-7|5.

75. Murray JJ, Church NL, Anderson WH, Bernstein DI, Wenzel SE, Emmett A, Rickard KA: Concurrent use of salmeterol with inhaled corticosteroids is more effective than inhaled corticosteroid dose increases. Allergy Asthma Proc 1999, 20:173-180.

76. van Noord JA, Schreurs AJ, Mol SJ, Mulder PG: Addition of salmeterol versus doubling the dose of fluticasone propionate in patients with mild to moderate asthma. Thorax 1999, 54:207-2। 2 .

77. Vermetten FA, Boermans AJ, Luiten WD, Mulder PG, Vermue NA: Comparison of salmeterol with beclomethasone in adult patients with mild persistent asthma who are already on low-dose inhaled steroids. J Asthma 1999, 36:97-106.

78. Ind PW, Dal Negro R, Colman NC, Fletcher CP, Browning D, James $\mathrm{MH}$ : Addition of salmeterol to fluticasone propionate treatment in moderate-to-severe asthma. Respir Med 2003, 97:555-562.

79. Juniper EF, Svensson K, O'Byrne PM, Barnes PJ, Bauer CA, Lofdahl CG, Postma DS, Pauwels RA, Tattersfield AE, Ullman A: Asthma quality of life during I year of treatment with budesonide with or without formoterol. Eur Respir J 1999, I 4:1 038-1043.

80. Santanello NC, Barber BL, Reiss TF, Friedman BS, Juniper EF, Zhang $\mathrm{J}$ : Measurement characteristics of two asthma symptom diary scales for use in clinical trials. Eur Respir $J$ I997, 10:646-65I.

81. Bouros D, Bachlitzanakis N, Kottakis J, Pfister P, Polychronopoulos V, Papadakis E, Constantopoulos S, Froudarakis M, Sichletidis L, Siafakas $\mathrm{N}$ : Formoterol and beclomethasone versus higher dose beclomethasone as maintenance therapy in adult asthma. Eur Respir J 1999, 1 4:627-632.

82. Kankaanranta $H$, Lindsay MA, Giembycz MA, Zhang $X$, Moilanen $E$, Barnes PJ: Delayed eosinophil apoptosis in asthma. J Allergy Clin Immunol 2000, 106:77-83.

83. Nielson CP, Hadjokas NE: Beta-adrenoceptor agonists block corticosteroid inhibition in eosinophils. Am J Respir Crit Care Med 1998, 157:184-191.

84. Kips JC, O'Connor BJ, Inman MD, Svensson K, Pauwels RA, O'Byrne PM: A long-term study of the antiinflammatory effect of lowdose budesonide plus formoterol versus high-dose budesonide in asthma. Am J Respir Crit Care Med 2000, I6 I:996-100 I.

85. Li X, Ward C, Thien F, Bish R, Bamford T, Bao X, Bailey M, Wilson JW, Haydn WE: An antiinflammatory effect of salmeterol, a long-acting $\beta_{2}$-agonist, assessed in airway biopsies and bronchoalveolar lavage in asthma. Am J Respir Crit Care Med 1999. | 60:|493-1499. 
86. Gardiner PV, Ward C, Booth H, Allison A, Hendrick DJ, Walters EH: Effect of eight weeks of treatment with salmeterol on bronchoalveolar lavage inflammatory indices in asthmatics. $\mathrm{Am} \mathrm{J}$ Respir Crit Care Med 1994, I 50:I006-IOII.

87. Mclvor RA, Pizzichini E, Turner MO, Hussack P, Hargreave FE, Sears $M R$ : Potential masking effects of salmeterol on airway inflammation in asthma. Am J Respir Crit Care Med 1998, I 58:924-930.

88. Orsida BE, Ward C, Li X, Bish R, Wilson JW, Thien F, Walters EH: Effect of a long-acting $\beta_{2}$-agonist over three months on airway wall vascular remodeling in asthma. Am J Respir Crit Care Med 2001, 164:117-121.

89. Tattersfield AE, Postma DS, Barnes PJ, Svensson K, Bauer CA, O'Byrne PM, Lofdahl CG, Pauwels RA, Ullman A: Exacerbations of asthma: a descriptive study of $\mathbf{4 2 5}$ severe exacerbations. The FACET International Study Group. Am J Respir Crit Care Med 1999, I 60:594-599.

90. Matz J, Emmett A, Rickard K, Kalberg C: Addition of salmeterol to low-dose fluticasone versus higher-dose fluticasone: an analysis of asthma exacerbations. J Allergy Clin Immunol 200I, 107:783-789.

91. Dworski R, FitzGerald GA, Oates JA, Sheller JR: Effect of oral prednisone on airway inflammatory mediators in atopic asthma. Am J Respir Crit Care Med 1994, I49:953-959.

92. O'Shaughnessy KM, Wellings R, Gillies B, Fuller R: Differential effects of fluticasone propionate on allergen-evoked bronchoconstriction and increased urinary leukotriene $E_{4}$ excretion. Am Rev Respir Dis 1993, I47:1472-1476.

93. Price DB, Hernandez D, Magyar P, Fiterman J, Beeh KM, James IG, Konstantopoulos S, Rojas R, van Noord JA, Pons M, Gilles L, Leff JA, for the clinical outcomes with montelukast as a partner agent to corticosteroid therapy (COMPACT) international study group: Randomised controlled trial of montelukast plus inhaled budesonide versus double dose inhaled budesonide in adult patients with asthma. Thorax 2003, 58:21।-216.

94. Vaquerizo MJ, Casan P, Castillo , Perpina M, Sanchis, Sobradillo V, Valencia A, Verea H, Viejo JL, Villasante C, Gonzalez-Esteban J, Picado $C$ : Effect of added montelukast to inhaled budesonide on control of mild to moderate asthma. Thorax 2003, 58:204-2II.

95. Laviolette M, Malmstrom K, Lu S, Chervinsky P, Pujet JC, Peszek I, Zhang J, Reiss TF: Montelukast added to inhaled beclomethasone in treatment of asthma. Montelukast/Beclomethasone Additivity Group. Am J Respir Crit Care Med 1999, I 60: I862-I868.

96. Robinson DS, Campbell D, Barnes PJ: Addition of leukotriene antagonists to therapy in chronic persistent asthma: a randomised double-blind placebo-controlled trial. Lancet 200I, 357:2007-20II.

97. Currie GP, Lee DKC, Haggart K, Bates CE, Lipworth BJ: Effects of montelukast on surrogate inflammatory markers in corticosteroid-treated patients with asthma. Am J Respir Crit Care Med 2002, 167:1232-1238.

98. O'Sullivan S, Akveld M, Burke CM, Poulter LW: Effect of addition of montelukast to inhaled fluticasone propionate on airway inflammation. Am J Respir Crit Care Med 2003, I 67:745-750.

99. Leigh $R$, Vethannayagam D, Yoshida M, Watson RM, Rerecich $T$, Inman MD, O'Byrne PM: Effects of montelukast and budesonide on airway responses and airway inflammation in asthma. Am J Respir Crit Care Med 2002, 166:1212-1217

100. Virchow JC, Prasse A, Naya I, Summerton L, Harris A, the Zafirlukast Study Group: Zafirlukast improves asthma control in patients receiving high-dose inhaled corticosteroids. Am J Respir Crit Care Med 2000, I 62:578-585

101. Ducharme FM: Anti-leukotriene as add-on therapy to inhaled glucocorticoids in patients with asthma: systematic review of current evidence. BM/ 2002, 324: I545-I55|

102. Ducharme F, Hicks G, Kakuma R: Addition of anti-leukotriene agents to inhaled corticosteroids for chronic asthma (Cochrane Review). In In: The Cochrane Library Issue I Oxford:Update Software; 2003.

103. Weinberger M, Hendeles L: Theophylline in asthma. N Engl J Med 1996, 334: I380-1388.

104. Rivington RN, Boulet LP, Cote J, Kreisman H, Small DI, Alexander M, Day A, Harsanyi Z, Darke AC: Efficacy of Uniphyl, salbutamol, and their combination in asthmatic patients on high-dose inhaled steroids. Am J Respir Crit Care Med 1995, I 5 I:325-332.

105. Youngchaiyud P, Permpikul C, Suthamsmai T, Wong E: A doubleblind comparison of inhaled budesonide, long-acting theo- phylline, and their combination in treatment of nocturnal asthma. Allergy 1995, 50:28-33.

106. Evans DJ, Taylor DA, Zetterstrom O, Chung KF, O'Connor BJ, Barnes PJ: A comparison of low-dose inhaled budesonide plus theophylline and high-dose inhaled budesonide for moderate asthma. N EnglJ Med 1997, 337:|4I2-1418.

107. Ukena D, Harnest U, Sakalauskas R, Magyar P, Vetter N, Steffen H, Leichtl S, Rathgeb F, Keller A, Steinijans VW: Comparison of addition of theophylline to inhaled steroid with doubling of the dose of inhaled steroid in asthma. Eur Respir J 1997, I 0:2754-2760.

108. Lim S, Jatakanon A, Gordon D, Macdonald C, Chung KF, Barnes PJ: Comparison of high dose inhaled steroids, low dose inhaled steroids plus low dose theophylline, and low dose inhaled steroids alone in chronic asthma in general practice. Thorax 2000, 55:837-84I.

109. Nelson HS, Busse WW, Kerwin E, Church N, Emmett A, Rickard K, Knobil K: Fluticasone propionate/salmeterol combination provides more effective asthma control than low-dose inhaled corticosteroid plus montelukast. J Allergy Clin Immunol 2000, 106:1088-1095.

I 10. Ringdal N, Eliraz A, Pruzinec P, Weber $\mathrm{H}-\mathrm{H}$, Mulder PGH, Akveld M, Bateman ED: The salmeterol/fluticasone combination is more effective than fluticasone plus oral montelukast in asthma. Respir Med 2003, 97:234-24I.

I I I. Bjermer L, Bisgaard H, Bousquet J, Fabbri LM, Greening AP, Haahtela T, Holgate ST, Picado C, Menten J, Balachandra Dass S, Leff JA, Polos PG: Montelukast and fluticasone compared with salmeterol and fluticasone in protecting against asthma exacerbation in adults: one year, double-blind, randomised, comparative trial. BM/ 2003, 327:89I

I 12. Fish JE, Israel E, Murray JJ, Emmett A, Boone R, Yancey SW, Rickard $K A$ : Salmeterol powder provides significantly better benefit than montelukast in asthmatic patients receiving concomitant inhaled corticosteroid therapy. Chest 200I, I 20:423-430.

I 13. Wilson AM, Dempsey OJ, Sims EJ, Lipworth BJ: Evaluation of salmeterol or montelukast as second-line therapy for asthma not controlled with inhaled corticosteroids. Chest 200I, I 19:1021-1026.

I 14. Nelson HS, Nathan RA, Kalberg C, Yancey SW, Rickard KA: Comparison of inhaled salmeterol and oral zafirlukast in asthmatic patients using concomitant inhaled corticosteroids. MedGenMed 200I, 3:3.

115. Busse W, Nelson H, Wolfe J, Kalberg C, Yancey SW, Rickard KA: Comparison of inhaled salmeterol and oral zafirlukast in patients with asthma. J Allergy Clin Immunol 1999, I03: I075- 080.

116. Yardakul AS, Calisir HC, Tunctan B, Ögretensoy M: Comparison of second controller medications in addition to inhaled corticosteroid in patients with moderate asthma. Respir Med 2002, 96:322-329.

I 17. Dompeling E, van Grunsven PM, van Schayck CP, Folgering H, Molema $J$, van Weel C: Treatment with inhaled steroids in asthma and chronic bronchitis: long-term compliance and inhaler technique. Fam Pract 1992, 9:161-166.

I 18. Bosley CM, Parry DT, Cochrane GM: Patient compliance with inhaled medication: does combining beta-agonists with corticosteroids improve compliance? Eur Respir J 1994, 7:504-509.

1 19. Kelloway JS, Wyatt RA, Adlis SA: Comparison of patients' compliance with prescribed oral and inhaled asthma medications. Arch Intern Med 1994, I 54: I 349- I 352.

120. Simon RA: Update on inhaled corticosteroids: safety, compliance, and new delivery systems. Allergy Asthma Proc 1999, 20: $16 \mid-165$

121. Gibson PG, Coughlan J, Wilson AJ, Abramson M, Bauman A, Hensley $M J$, Walters $E H$ : Self-management education and regular practitioner review for adults with asthma (Cochrane Review). In In: The Cochrane Library Issue I Oxford:Update Software; 2002. 